\title{
Performing Mediaeval Hebrew Poetry
}

\author{
Reuven Tsur*
}

\begin{abstract}
This is an instrumental exploration of theoretical issues related to the vocal performance of Mediaeval Hebrew pegs-and-cords meter, of which we have neither authentic recordings, nor verbal descriptions of actual performances of the time. Consequently, I am exploring only possibilities implied by poetic structures as embodied in later performances, not in actual authentic performances. But, in my earlier writings, I have extensively explored similar issues in English, Hungarian and modern Hebrew poetry, as recorded by experienced readers. The pegs-and-cords meter is a unique quantitative system based on systematic (not necessarily regular) alternation of schwa mobile and full vowels. The time ratio between the two is supposed to be 1:2, 1:3 or 1:4. Some scholars believe that in Jewish Yemenite liturgy the authentic performance has been preserved. This article is focused on one brief liturgical masterpiece by Shlomo Ibn Gabirol, submitting to computer analysis a modern recital of it, and a sung performance of a Yemenite master. Regarding the correspondence of language and versification, eleventh-century Hebrew poets explicitly distinguished between two possibilities: word endings may or may not coincide with the ending of a metric foot. I have investigated on the computer whether it is possible to convey continuation and discontinuation at the same time by a single voice, where word endings and metricfoot endings do not coincide. Neither performer observed the conflicting endings consistently, but both provided evidence that it is possible to identify the problems and solve them by vocal manipulation. In the Yemenite masters' performances, computer measurements could not establish that the schwas are consistently shorter than the vowels. Furthermore, poetic rhythm requires the simultaneous perception of two versification levels at least: a wider unit (the verse line or a hemistich), and the metric feet that divide it. Psychologically, simultaneous presence implies being contained within the same span of short-term memory. In the Yemenite masters' performances, the wider units exceed by far the span of short-term memory, owing to repetition of phrases and drawn-out embellishments, so that the poems' rhythms could not be preserved. In the 16th-17th century there were Jewish musicians in Western Europe who composed liturgic music in the baroque tradition, some of it to pegs-and-cord texts. In a brief pilot I point out the differences in aesthetic conception between this baroque music and the Yemenite master. Finally, Mediaeval poets treated a schwa+vowel as a unit called "peg". Here the question of psychological reality arises. The issue at stake is whether two immediately-observable constituents can be experienced at a more abstract level as one unit. The precedent of what generative metrists call "disyllabic
\end{abstract}

* Author's address: Reuven Tsur, Tel Aviv University, Tel Aviv 69978, Israel; email: tsurxx@tauex.tau.ac.il. 
occupancy of metrical position" in English poetry suggests a positive answer. "Power" at the end of an iambic line may be perceived as occupying one or two metrical positions. Computer analysis shows systematic acoustic differences between instances in which two syllables occupy one or two positions. We cannot know, however, what was actually the case with the peg, since we do not know how it was performed; in this respect, we have demonstrated only a possibility.

Keywords: Approaches to poetic rhythm; approaches to perceived qualities of poetry; rhythmical performance; performance of mediaeval Hebrew poetry; cognitive poetics; instrumental phonetics.

\section{Setting the Problem}

The pegs-and-cords meter was imported to Hebrew poetry from contemporary Andalusian Arab poetry. ${ }^{1}$ To be precise, it was imported and changed en route, because in Hebrew there are no long and short vowels as in Arabic (or in Greek and Latin, for that matter). The poets thought of their meters in terms of long units called "pegs", consisting of a schwa plus full vowel, and a short unit called "cords", consisting of a full vowel (in all sorts of configurations). Schirman (1979) thought that it was more parsimonious to simplify the system and speak of schwas and full vowels (irrespective of the ensuing letters), marking the schwa as short and the vowel long. In this article, I am following Schirman, with the exception of the section on psychological reality. The poets had an ambivalent attitude towards this meter. One of the great masters of eleventh-century pegs-and-cords poetry, Yehuda Halevy, argued that it is foreign to the spirit of Hebrew, and corrupts spoken language. ${ }^{2}$

Nothing reliable is known about how the pegs-and-cords meter was performed in the eleventh century. I am going to put forward my argument in four

\footnotetext{
1 I wish to thank Idith Eynath-Nov, Uria Kfir and Chen Gafni who advised my project as a think team, and to express my special gratitude to Avner Bahat, without whose project this research could not take place.

2 Yehuda Halevy wrote in his "Essay on Meter":

I was reminded of the honorable Ibn Saïd's words about the meters used by the new poets, [those] who don't care about the corruption of the Hebrew language. However, truly, measuring Hebrew in Arabic meters deserves censure, because it corrupts Hebrew speech, since it deprives it of ultimate and penultimate stress, that distinguish between noun and verb as in אוֵֹِ [in English, too, words like "present, object, subject" are verbs when the last syllable is stressed, and nouns when the last-but-one syllable is stressed - RT]; that distinguish between

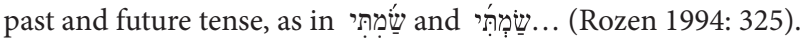


sections. All four try to make sense with the help of instrumental phonetics of the little that can be known from traditional sources as to how the pegsand-cords meter can be performed and may affect the perceiver. Two leading authorities (in fact, the only ones to write on the subject), Schirman (1979) and Bahat (2016), suggest that the Yemenite masters of liturgic poetry have preserved to this very day the tradition initiated in eleventh-century Spain. The first two sections submit to computer analysis performances of the same poem by Ibn Gabirol performed by a Yemenite master (second section), and a "modern" reading by a radio announcer of Yemenite origin (first section). In the modern reading the computer revealed vocal strategies that resolve conflicts between the versification pattern and the linguistic pattern. In the Yemenite master's performance the computer revealed one such solution; but it also revealed that the schwas are not necessarily shorter than the vowels, as they ought to be according to the rules. A theoretical analysis suggests that, owing to repetitions and drawn-out embellishments, verse lines exceed in this performance the span of short-term memory, disrupting rhythm. The third section is a short pilot on the pegs-and-cords metre in Jewish Baroque music. The final section raises a more general question about the pegs - their psychological reality: whether a schwa plus vowel can be experienced as one unit.

In his article "How should One Recite the Metered Verse of our Mediaeval Poets?", Hayim Shirman - the greatest scholar of Mediaeval Hebrew poetry in all times - proposes rules for the putative performance of the pegs-and-cords meter in mediaeval Hebrew poetry. He does this very cautiously, even though he uses "should", in the sense of "indicating a desirable or expected state". The present article has more modest claims: How can one perform this poetry. Shirman's approach is prescriptive; the present article professes to be descriptive: not how should one solve problems in the text, but how did or did not reciters succeed in solving rhythmic problems in the text. It focuses on perfor-

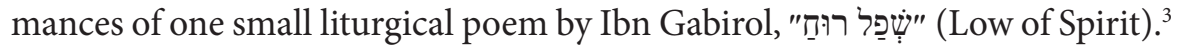

Schirman observes: "We have today no reliable tradition regarding the performance of poems based on the Spanish meter. However, one may doubtless benefit a lot in working out this problem from readings prevailing among present-day Arabic-speaking Jews. I mean especially those who have not yet been exposed to the sounds of European languages" (1979: 84). The ethnomusicologist Avner Bahat and his wife Naomi recorded an enormous collection

\footnotetext{
3 Success judgments in this field require considerable informed experience. I have not had, therefore, recourse to statistical research methods with a great number of naïve "subjects", borrowed from the social sciences, but rather to the informed judgments of a team of experts, two in the study of mediaeval Hebrew poetry, and one in phonology (named in footnote 1).
} 
of songs by the various ethnic groups in Israel, among them songs from the Yemenite Diwan. In his article on Ibn Gabirol, Bahat reports a most interesting phenomenon regarding the changes undergone by Yemenite "singers of songs", after immigrating to Israel. In recordings immediately after immigration, they observed all the rules of the meter; in recordings a few years later, the performance of the same singers deteriorated, as far as the observation of meter was concerned.

Shirman, who had wide musical education too, proposed to formulate theoretically the principles of performing the pegs-and-cords rhythm. These are some of the principles proposed:

The clearest and most convenient way to indicate the reading of short and long syllables seems to me to use musical notes. Supposing that we indicate a long syllable by a quarter of a note( (১), we may indicate a short syllable as half the length

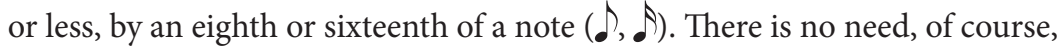
to suppose that the proportion should be 1:2, as postulated by some scholars of ancient Greek metrics. In view of the short pronunciation of the schwa mobile, it seems to me that the proportion 1:3 or 1:4 would be more natural (1979: 85).

He suggests that observance of these time-proportions allows to maintain linguistic stresses without disturbing the rhythmic organization. Schirman exemplifies, according to his method, the most widespread meters. I will

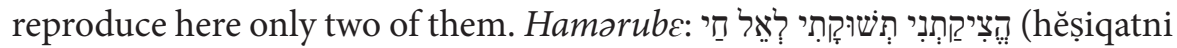
təšuqati l?əel ḥaj):

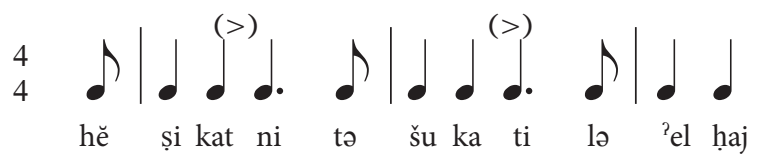

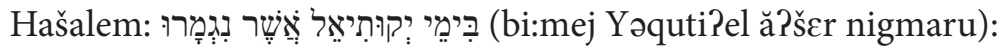

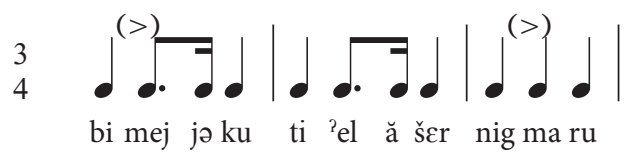

Such a notation imposes an a-priori order on the text, detached, to a considerable extent, from pronunciation in ordinary language. Yehuda Halevy, the great mediaeval Hebrew poet, himself criticized the unnaturalness of such pronunciation (even though he went along with it in his poetry). In this article, I will make use of Avner Bahat's collection of tapes, exploring two options offered 
by it: On Bahat's website, there is a collection of readings from the Yemenite Diwan, by Mošc Hovav, a former senior announcer at the Israeli radio, himself of Yemenite origin. These readings don't presume to reflect the authentic performance of meters in the Middle Ages, nor Schirman's recommendations. It is a special use of spoken language that may, nevertheless, illuminate some significant aesthetic problems involved. I will analyze his reading of one of Ibn Gabirol's short masterpieces, and a traditional performance of the same poem, by one of the Yemenite masters.

\section{Theoretical and Methodological Background Perceived qualities and their assessment}

A poem has an objectively describable structure and perceived qualities. An adequate theory must cope with both. Perceived qualities traditionally belong to the domain of impressionist criticism. The impressionist critic conveys his impressions from the text, but does not know how to relate them to the text's structure. Analytic criticism, by contrast, describes the structures of the text, but frequently it is not clear what is the human significance of those structures. Cognitive poetics offers linguistic and psychological hypotheses to systematically relate perceived human qualities to the analyzed structures. How can we know what is the perceived quality of a poem? I shall put forward three possible approaches to the issue.

1. The most objective approach has been propounded by Cynthia Whissel. She used "a computer program which is capable of scoring texts in terms of their emotional tone [...]. The program accomplishes this by comparing the text, one word at a time, to a Dictionary of Affect which includes people's ratings of pleasantness and activation for close to 4,700 different words" (1999: 24-25).

2. The most widespread method in the humanities is a statistical method imported from the social sciences, administering a stimulus-response questionnaire to a group of subjects. The quality that receives the greatest number of votes is the perceived quality of the poem.

The deficiency of both methods may be demonstrated through the following line by the great Hebrew poet Nathan Alterman:

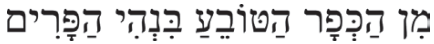

min hakfar hatove؟a binhi haparim

From the village drowning in the moan of the oxen 
Many years ago I asked students in a graduate seminar to say about this verse line anything that seems to them relevant, without any guiding questions. Some students found it exceptionally unpleasant, some found it exceptionally pleasant. The relative numbers are irrelevant here. As to how they reached these opposite evaluations, I found out this. Students are taught to look for connotations of words. Those who looked for the connotations of "one word at a time" found this verse line exceptionally unpleasant, owing to the connotations of "drowning" and "moan". Students who responded to the verse line as an integrated whole found it exceptionally pleasant. Applying a hypothesis to the line based on what Ehrenzweig (1970: 135), following Freud, called "Oceanic dedifferentiation" may explain why being immersed in an abstraction may be perceived as pleasant in poetry (see Tsur 2012: Chapter 4). Evaluation depends here on the strategy applied. If you attend to the connotations of "one word at a time", then you will judge this verse line unpleasant; if you attend to the verse line as a whole, then you may judge it as pleasant. It is reasonable to assume that aesthetic effects and aesthetic value reside in aesthetic wholes rather than in individual words. This may indicate which strategy is more adequate.

There are good chances that in complex aesthetic issues the less sophisticated rather than the more adequate strategy will win the day in a statistical investigation. The Affective Dictionary method precludes $a b$ ovo response to the line as a whole. In a statistical study, if the experimenter explains to his subjects what strategy is relevant to the experiment, he predetermines the results. Statistical experiments are very useful in an attempt to discover psychological mechanisms, as in Fodor et al.s experiments to test the psychological reality of syntactic boundaries, or Fry's experiments to discover the relative weight of acoustic cues for linguistic stress (see below); but where complex aesthetic qualities are concerned, they may be misleading. There may be some insurmountable problems of communication. Various subjects perform the same text differently, and thus respond to different aesthetic objects; most researchers are not aware of this problem.

Moreover, Joseph Glicksohn, Chanita Goodblatt and myself tested the effect of professional training and personality style on the response to poetry (Tsur 2006: Chapter 3). Our participants were university lecturers and professors, divided into two times two groups: professionals in literature or in other humanities and the social sciences; and high or low on a certain personality variable. In several tasks we received exactly opposite results from participants high and low on the personality variable; and in some tasks, one group (literary professionals low on the personality variable) performed differently from the other three groups. So, with complex aesthetic issues, with great numbers of 
participants we obtain only the lowest common denominator of several strategies and personality styles, without any control over these variables.

The current trend in the humanities is to aspire to the scientific rigour of the exact sciences. Scholars in the humanities, however, are not aware of what the philosophers of science know very well: that in physics too various questions require different degrees of rigour. The Oxford philosopher J. J. C. Smart in his classical paper on theory construction propounds the following argument.

Roughly speaking, we may say that within a theory or within the description of fact we are on one level of language, but when we step from the level of theory to the level of fact or vice versa, we are in a region where expressions like 'make more plausible, 'lead us to expect that', or 'strongly suggest' apply, but where the logical relations of implication and contradiction do not strictly apply. (Smart 1953: 239)

“'Rigour' in the sense it is pursued in pure mathematics is not an ideal in applied mathematics. The conception of 'rigour' involved in physics is that whereby it makes sense to say 'rigorous enough"' (idem, 237). Smart makes these statements with reference to the Kinetic Theory of Gases. In physics, then, such leaps can be made only in a hypothetical language. Thus, in matters related to poetic rhythm too, when leaping from observational facts to theory and vice versa, expressions like 'make more plausible', 'lead us to expect that', or 'strongly suggest' apply, but where the logical relations of implication and contradiction do not strictly apply. This is the case, even more so, when we leap from the description of a text to its perceived quality. This is the best we can do in physics, and we should not aspire to more in aesthetic discourse either.

3. Consequently, we need to adopt some method proposed by analytic philosophers. The philosopher Morris Weitz (1956: 35) suggests that in aesthetics "the role of the theory is not to define anything but to use the definitional form, almost epigrammatically, to pin-point a crucial recommendation" as to what to look for and how to look at it in art). Thus, the best we can do when discussing perceived qualities of a poem is to give a structural description of the text by exact technically defined terms, and then make a leap to theoretical considerations in such terms as 'make more plausible', 'lead us to expect that', or 'strongly suggest'; and an additional leap as a crucial recommendation as to what to look for in the poem and how to look at it. Such a crucial recommendation does not exclude alternative recommendations; we should judge the recommendations in light of our theoretical assumptions, the text's structure and of what we know about relevant psychological processes. Since such 
vague terms cannot be avoided in crucial leaps in physics or aesthetics, such an approach renders, at least, critical discourse discutable - that is, capable of being investigated by reasoning or argument.

\section{Musical notation and the sound recorders}

The instrumental study of poetic rhythm has been around since the beginning of the twentieth century. Most of the early researchers thought they were measuring the rhythm of the poem, and didn't realize that they were measuring only a casual performance of it. Wellek and Warren (1949) and Wimsatt and Beardsley (1959) harshly criticised this naïve approach. Wellek and Warren proposed, instead, a distinction between three dimensions of poetic rhythm: language, versification and performance. My work added to this conception the notion that performance is a problem-solving activity when the linguistic pattern and the versification pattern conflict. Halle and Keyser $(1966 ; 1971)$ reinvented the first two of these patterns, and explicitly declared that they had nothing to say about performance. Later generative metrists explicitly rejected any talk of performance. Halle and Keyser set out to devise a system that generates all metrical lines but no unmetrical ones. By the same token the system is a powerful tool to foreground conflicts between language and versification. Later generative metrists sought to eliminate conflicts. Kiparsky $(1975 ; 1977)$ offers "optional rules" to eliminate conflicts, rather than to resolve them. My own work explores here and elsewhere how conflicting patterns of language and versification can be accommodated in a rhythmical performance. The present article does not just provide additional evidence to my theory; it uses my earlier findings to penetrate into the terra incognita of the vocal performance of Mediaeval Hebrew meter.

In the first half of the twentieth century there was a school that used musical notation to mark rhythm in syllabotonic meter. Wellek (in Theory of Literature [Wellek, Warren 1949: 156] and his contribution to Sebeok's Style in Language [Wellek 1960: 414]) and Wimsatt and Beardsley attacked this approach. The musical notation method acted in the service of "proportional timing", to solve a puzzle. The iambic pentameter is supposed to consist of five units of unstressed and stressed syllables; but such lines are extremely rare in English poetry. In the first 165 lines of Paradise Lost there are exactly three such lines.

In spite of the visual similarity, there is an all-important difference between the two methods of musical notation. The method criticized by Wellek, 
Wimsatt and Beardsley forces on syllabotonic meter the alien conception of proportional timing (refuted in all instrumental studies), whereas Mediaeval Hebrew meter (or classical Greek and Latin meter) is based on time relationships between theoretically long and short units. Thus, Schirman and Bahat used musical notation to bring out the underlying principle - Schirman $a$ priori, Bahat after the event. ${ }^{4}$

\section{Conflicting Intonation Contours}

The received view among researchers of English Prosody, formulated by Seymour Chatman $(1965,1966)$, is that in case of conflict between the intonation contours of language and versification, the performer can convey in his one voice only one intonation contour, and suppress the other. Indeed, according to this conception, if the metric foot boundary and the word boundary are incongruent, the performer can convey only one of them, but not the other. The 2012 version of the Princeton Encyclopedia of Poetry and Poetics still gives Chatman's view as the view of performance. In my 1977 book I claimed that in spoken language there is redundancy of acoustic cues for ending: at the sentence ending, for instance, we make a pause, move down with intonation and prolong the last speech sounds. In case of conflicting linguistic and versification units one may split the acoustic cues. In my 2012 book I provided ample illustration of this. In some of my publications (e.g., Tsur, Gafni 2019) I provide examples of doctoring performances of enjambments that indicate only continuity at the line ending, so as to indicate continuity and discontinuity at the same time. In the present article I demonstrate this at a more fine-grained level, of words running over foot boundaries.

\section{Essentials of Mediaeval Hebrew Versification}

Poetic meter frequently consists in more or less regularly alternating syllables of opposing character: long and short syllables or stressed and unstressed syllables. In some Chinese poetry, we find mandatory tonal alterations between adjacent positions within a line. The Mediaeval Hebrew corpus under

\footnotetext{
4 In his 1935 Approaches to the Science of English Verse (reprinted in 1975) Wilbur Schramm gives an overview of the early sound recorders and proportional (or equal) timers. Schramm himself offers an admirable instrumental analysis of accommodating conflicting linguistic and versification patterns in a performance.
} 
discussion is based on (not necessarily regular) alternation of schwa mobile

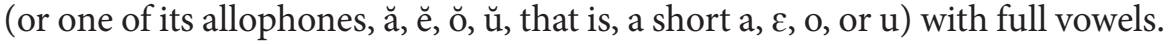
Schwa mobile is what in English would be called a reduced vowel.

In this poetry, the verse line is usually divided into two (or more) formal segments called "flanks"; each flank consisting of three or four feet (rarely two). Hamərube and hašalem are the two most frequent meters (in this order). Both meters are based on one short and three long units, that is, one schwa mobile (or one of its allophones), and three full vowels. They differ in the placement of the schwa. In hamarube, the schwa comes first, followed by three full vowels; in hašalem, it follows two full vowels, before the last full vowel. Schwa mobile is what in English would be called a reduced vowel, in phonetic transcript marked by "ə". Using English words, a hamarube foot would look like "about painting" [obaut peIntIn]. The third foot is foreshortened (one schwa mobile and only two full vowels). A full flank would look like "about painting / about painting / about paint" [obaut peintın / obaut peinting / obout peint] (stresses not counted; the slash indicates foot boundary). A hašalem foot would look like "his cutlery" (hız kıtləri). A full flank would look like "hız kıtləri / hız kıtləri / hiz kıtləri". In the last foot, the schwa may be omitted before rhyme, as in "his cutting". This metric system is typically associated with monorhyme: all the lines have the same end rhyme (strophic poems are associated with a kind of syllabic meter, schwas not counted).

\section{Congruence and Incongruence Between Language and Versification}

In my works on poetry of more modern literatures (English, Hungarian, Modern Hebrew) I came to the conclusion that it is not enough to concentrate in prosodic studies on the sequence of opposing syllables only. One must pay attention to additional dimensions, such as congruence or incongruence between linguistic and versification units. This generates unity in complexity, of great aesthetic interest. Mediaeval poets were very much aware of the problem of congruence and incongruence between linguistic and versification units. In the so-called "ornamental opening", the two flanks of the first verse line rhyme with each other; in addition, in this line, the end of each metric foot must coincide with a word boundary (see the first line of Ibn Gabirol's poem below). In all the other lines, the poet is free to create incongruence between linguistic and versification units. Many present-day readers perceive in such congruence some degree of monotony, whereas in the incongruence 
they frequently perceive complexity, of great aesthetic interest. Congruence is perceived as static, incongruence as dynamic. Mediaeval poets and their readers felt, presumably, a sense of certainty, control and power in congruence, while the mid-rhyme clearly articulates the coinciding flank and phrase boundaries, reinforcing this sense of stability.

To indicate the perceived quality of this opposition between the static and dynamic effects, I shall illustrate it through the discussion of an exception that proves the rule. In a short masterpiece on frustrated love by Ibn Khalphun, contrary to all other instances of the age, the rules of ornamental opening are applied to the second line, not to the first line. I shall quote only the first two of the four monorhymed verses. Scholars and critics usually do only the book-keeper's job: they point out that in some instances the first line conforms with the rules of ornamental opening. By contrast, I will point out significant interaction between the meaning and the formal structure.

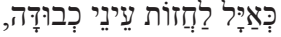

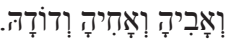

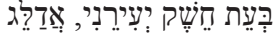

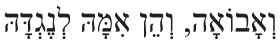

bəSet héšcq yəSiréni Pădalég

s 1 l l/ s lll/s ll/

vəPavó?a vəhén Pimá lənegdá

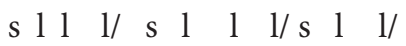

When desire awakens me I bound

I come and lo her mother before her
kəPayál lahăzót Seyney kəvudá

s 1 l l l/ s 1 l l l/ s $11 /$

vəPavíha və?ahíha vədodá

s 1 l l/s s 1 lll s l l/

like a stag to see the eyes of the honorable (girl) and her father and her brother and her uncle

The letters s and 1 under the transliteration lines signify short and long syllables; the slashes mark foot boundaries; the sharp accents mark linguistic stress. In the second line of this poem, the first flank rhymes with the second flank; and each foot boundary coincides with a word boundary. Not so in the first line, where there is no mid-rhyme, and a foot boundary occurs in the middle of the word "la/hăzot".

Semantically, the verb "bound" and the simile "like a stag" suggests fast, cheerful forward movement in expectation of the meeting. "I come" in the next line continues this movement. This, however, is followed by a series of nominal phrases that enumerate the girl's relatives surrounding her, suggesting a sudden cessation of motion, abrupt arrest. This contrast between cheerful movement and embarrassed arrest is reinforced by the "inverted" ornamental opening. In the first line there is incongruence between linguistic and versification units 
on two levels: the verb phrase "I bound like a stag" runs over the flank boundary, and the verb "lahăzót" (to see) runs over a foot boundary, enhancing the dynamic movement. In line 2 , by contrast, every foot boundary coincides with a word boundary suggesting stability, and the first flank apparently ends with a complete nominal clause "and lo her mother [is] before her", constituting a stable closure, reinforced by the mid-rhyme. The sequel, however, reopens the closed unit by a series of additional relatives. The text makes a very sophisticated use of the polysyndeton (multiple conjunctions). Each item in the second flank begins with "and" ( $v a-$ ). This is, apparently required by the meter (a schwa mobile). But here it has a rhetorical function too. In Greek rhetoric, conjunctions are deliberately inserted into a sentence for the purpose of "slow[ing] up the rhythm of the prose" so as to produce "an impressively solemn note". Here it has a very different purpose. The conjunction "and" is usually inserted before the last item of a list, to indicate that this is the end. In the present instance, however, the effect is the gradual increase of the shock. Each item beginning with "and" suggests that "this is the end", but is followed by yet another item beginning with "and". Briefly, the "inverted" ornamental opening impinges on the reader's perception the contrast between the fast, cheerful movement and the abrupt embarrassed arrest, by all possible means of semantics, syntax and versification (I have discussed this poem in detail in Tsur 1999).

\section{Mošz Hovav Reads Ibn Gabirol}

In what follows, we shall explore whether the reciter can, with his single voice, convey simultaneously the conflicting linguistic and versification patterns. I have explored this question at great length with reference to English poetry of various ages, as performed by leading British actors. Avner Bahat's project made it possible for me to probe into the recital of Mediaeval Hebrew poetry. From Moš Hovav's readings I gather that he was not aware of this theoretical problem, but sometimes he discerned it intuitively, and solved it in the best possible manner. However, quite frequently, he ignored it. Consequently, one may not assume a consistent conception underlying his reading in the spirit of my foregoing analysis, but one may find in them an answer to the following questions: Is there a possibility to convey in one reciter's voice, simultaneously, the conflicting streams of language and versification in Mediaeval Hebrew poetry?, and, if yes, What it sounds like? If the answer is positive, it does not mean that that's how the Spanish poets (or the Yemenite singers) performed the poems, only that there is at least one way to perform the poems in this 
manner. The rest of this article is devoted, as I said, to a short masterpiece by Ibn Gabirol from the Yemenite Diwan, as performed by Moš Hovav, and one of the Yemenite masters.

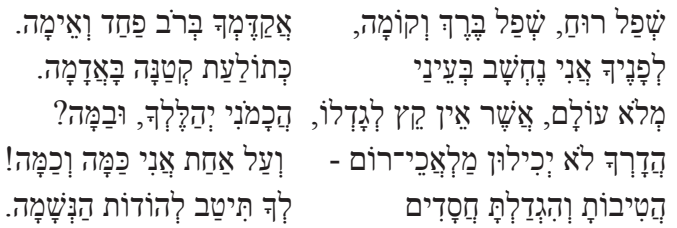

šəfal ruaḥ, šəfal berekh vəqoma,

Păqademkha bərov pahad vəجejma.

ləfanckha Păni neḥšav bəイejnaj

kətolaৎat qətana baجădama.

məlo? Solam, Păšcr Pen qeș ləgodlo,

hăkhamoni jəhalelkha, ŭvama?

hădarkha lo jəkhilun mal?ăkhej rum - vəSal Paḥat Păni kama vəkhama!

hătivota vəhigdalta ḥ̆ăsadim

ləkha ti:tav ləhodot hanəšama

Low in spirit, low on knees and [low] of stature

I come before you in great fear and dread

In your presence I seem to myself

As a small worm in the soil

You, who fill the whole Universe, whose expanse has no end,

Can one like myself praise you, and how?

The angels on high cannot encompass your splendour

How much less could I

You have done good and extended your kindness

It's good for the soul to praise you

Let us $\underline{\text { listen }}^{5}$ to the poem read by Moše Hovav. Now let us focus on the second flank of the second line.

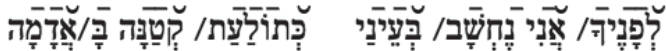

ləfanckha Păni ncḥšav bəSejnaj

kətolaৎat qətana baجădama.

In your presence I seem to myself

As a small worm in the soil

5 Sound files are available online at https://doi.org/10.12697/smp.2019.6.2.01. 


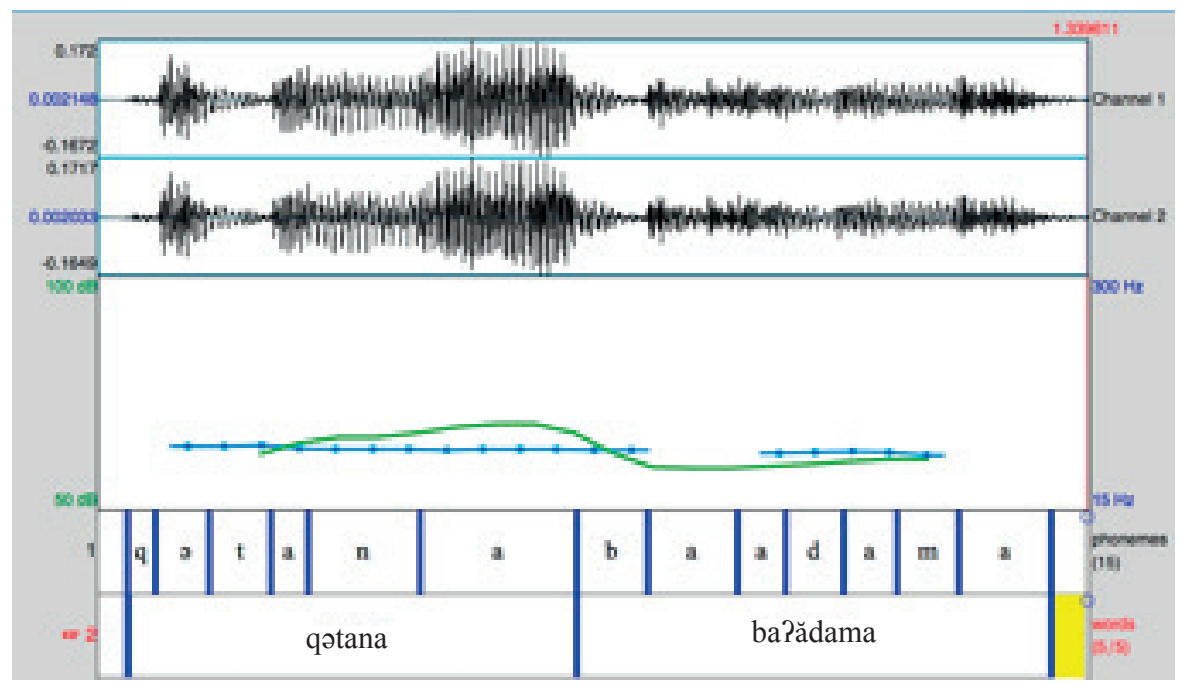

Figure 1. Wave plot, and pitch and intensity contours of "qətana bapădama"

In the first verse line of this poem, according to the rules of "ornamental opening", each foot boundary coincides with a word boundary, and the first flank rhymes with the second flank. In the second verse line, each foot boundary (except one) coincides with a word boundary. The exception is " - קְטָנָָּה (qəana ba/-). This is one of the instances, in which the reciter manages to convey that, in the sequence of words and metric feet, the units conflict after "qətana ba/", that is, their boundaries do not coincide. [Listen to the sequence "qətana ba?ădama".] A sensitive ear may discern here two conflicting streams of information: the word "qatana" ends in the middle of the foot, and the foot ends in the middle of the word "ba?ădama".

According to the British phonetician D. B. Fry's experiments, the acoustic cues for linguistic stress are increase in pitch, duration and amplitude, in this decreasing order of effectiveness. ${ }^{6}$ In phonetics, acoustic cue is a feature indicating the nature of a category perceived, such as speech sounds and suprasegmentals (stress, intonation). A look at Figure 1 indicates that the performer forwent the most effective cue for stress, the change of pitch; he relies

6 D. B. Fry (1956) explored experimentally these cues. The cue for linguistic stress is a mixture of pitch, duration and amplitude. Fry recorded words like "object, subject, present", and electronically manipulated pitch, duration and amplitude. Subjects had to decide whether they heard a verb (with stress on the second syllable), or a noun (with stress on the first syllable). He found that pitch change overrides duration, and duration overrides amplitude. Later he found that intonation inflection overrides all three. 
only on change of duration and intensity (the blue, dotted line indicates the pitch contour; the green, undotted line indicates the intensity contour; the left-to-right axis indicates duration). The stressed syllable "-na" (in "qətana") is longer and more intense than the other stressed syllables on either its sides: Its duration is 0.445921 milliseconds ( $\mathrm{ms}$ ); the duration of "-ma" in "ba?ădama" is $0.240743 \mathrm{~ms}$; whereas that of "-la" in "kətolaSat" is $0.352814 \mathrm{~ms}$. Such a long duration has an additional task: it indicates lack of progression, the end of something; in this case, the end of a word. This is required here, because there is no pause between the words "qətana ba?ădama". On the other hand, the increase in intensity adds emphasis that arouses expectation for the sequel, in this case, the next word. This effect is amplified by the fact that the intensity peak hits the vowel /a/ between its middle and its boundary, resulting in what British phoneticians would call "late peaking" or "delayed Peaking", and generating what the gestaltists call a "perceptual force" pushing forward (cf. Appendix). Thus, the syllable "ba" is separated from the preceding word and, at the same time, is required as continuation.

Two problems arise at this point. First, after "ba", the performer must indicate again continuation and discontinuation at the same time; continuation in the middle of the word, and discontinuation to indicate the end of a metric foot. Second, the vowel /a/ is repeated here, without a glottal stop required between them as indicated by the letter aleph. This hampers pronunciation. In Hebrew, the glottal stop aleph and the laryngeal stop ayin are phonemes. In English, too, the glottal stop may crucially affect meaning, without being a phoneme. Consider the sentence "I didn't say 'a name', I said 'an aim". In "an aim" we indicate discontinuity by inserting a glottal stop rather than a pause. In modern Hebrew, owing to the influence of European languages, glottal and laryngial stops are no longer observed, except by some Oriental Jews. In spite of his Yemenite origin, Mošc Hovav does not insert an aleph in the word "ba?ădama", but has recourse to another strategy. The transition between the two tokens of /a/ is smooth and "rounded"; discontinuity is generated by a change of pitch between the two tokens. By the same token, the change of pitch indicates that in spite of smooth continuation, something new begins here (a new metric foot). In Figure 1, vital information is missing precisely at this point in the intonation contour. In the course of reading, one does not discern the change of pitch, only that there are here two consecutive tokens of one vowel; but when one isolates the two tokens of /a/, one may hear the pitch differences with a naked ear [listen to the sequence]. In this way, the performer succeeded to convey, in his one voice, the counterpoint between the sequence of words and the sequence of metric feet at this point. In order to improve distinction, I have amplified intensity and doubled duration [listen]. 
The performer has recourse to similar acoustic means, with the necessary changes, in the words "bərov pahad", in the second flank of the first verse line [listen]. These are two words that constitute one metric foot. The performer's problem is how to indicate by his one voice that these are two words that constitute one metric foot. Listening to the flank "Păqademkha bərov pahad və?ejma" confirms that the performer does succeed to indicate this [listen]. As indicated by Figure 2, here too he forgoes the most effective acoustic cue for linguistic stress, change of pitch, and has recourse to duration and intensity. The syllable "-rov" is longer and more intense than any of the surrounding syllables, even though it is the second syllable of the subordinated noun in a genitive phrase. Here it works similarly to the stress in the previous example, "qətana barădama". The long duration of the syllable indicates, again, both stress and word boundary. The "knee" of the intensity curve near the vowel boundary, again, "pushes forward", to the next word, "pahad", across the pause. Thus, the two words are grouped together, to convey one metric foot, but are separated, to indicate two semantic units. At this point, one should point out that in this context, the acoustic cues work on a fairly abstract level; they don't indicate, specifically, a word boundary or a metric foot boundary, or a push to complete a word or a metric foot, but rather the boundary of something, and a push to complete something. It is the specific combination of linguistic and prosodic information that specifies boundary of what, or to complete what.

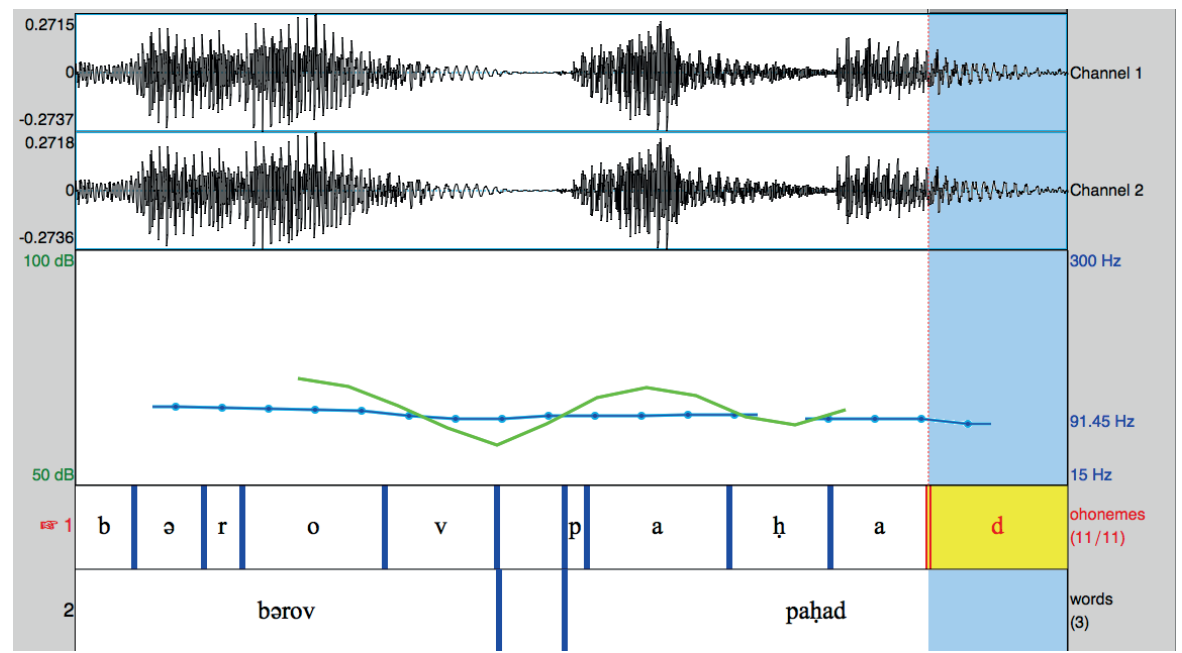

Figure 2. Wave plot, and pitch and intensity contours of "bərov pahad", 
Let us listen to this phrase.

hădarakh lo? jəkhilun mal?ăkhej rum -

Let us listen to this flank.

In this flank, one should notice two structural problems. The two words "lo? jəkhilun" (cannot encompass) constitute one phrase distributed between two metric feet; the metric foot "jokhilun mal" is distributed between two words. In the performance, three phenomena are noteworthy. In the conflict between the semantic sequence and the metric sequence, a boundary in one dimension intrudes upon a unit in the other dimension, and one may hear a mysterious forward-driving force across the intruding boundary, that is, from "lo" to "jəkhilun", and from "jəkhilun" to "mal". The third phenomenon is that the "ă" in "mal?ăkhej" (an allophone of schwa, that is, a short unit) is heard as unusually long. In other words, this verse line is a typical example of the uneven standard of this performance. The long "ă" is a blatant violation of the pegs-and-cords meter (in Figure 3 the unaided eye may clearly see that it is much longer than the / $\mathrm{a} /$ in the preceding syllable). Likewise, one would expect that the performer insert a glottal stop (as in "an aim"), as suggested by the aleph, as well as by the need to indicate the foot boundary. But there is no trace of it, either in listening, or in Figure 3. However, the "mysterious forward-driving force" we have discerned at two points in this reading is an elegant solution for the problem of intruding boundaries. Not as in the preceding examples, the performer makes use here of intonation, and in a brilliant manner. Both on the vowel /o/ (of "lo?") and the sequence /un/ (in "jəkhilun"), one may discern a small rise of the intonation contour. Here we must draw attention to a phenomenon I discovered in poetry reading with Jerry Knowles's help. Usually, the highest point of the intonation contour hits the word at the middle of the vowel in its stressed syllable. British phoneticians have discovered that in rare instances, the peak hits after the middle, near the vowel boundary, and sometimes after the vowel boundary on the ensuing liquid or nasal $(1, \mathrm{~m}, \mathrm{n}, \mathrm{r})$. They call this "late peaking". I have found that in poetry reading, this phenomenon is far more prevalent than in spoken language, and, according to gestalt theory, the later the peak, the stronger the forward push it exerts. In our case, one may see in Figure 3 that the intonation contour hits the word "lo?" near the far-end boundary, and in the word "jokhilun", it even overflows to the nasal /n/. Thus, the two words are grouped together as one phrase, in spite their belonging to two different feet; and in the sequence "jokhilun mal/", a push is felt across the first word boundary, to indicate that the two units belong to one metric foot (cf. Appendix). 


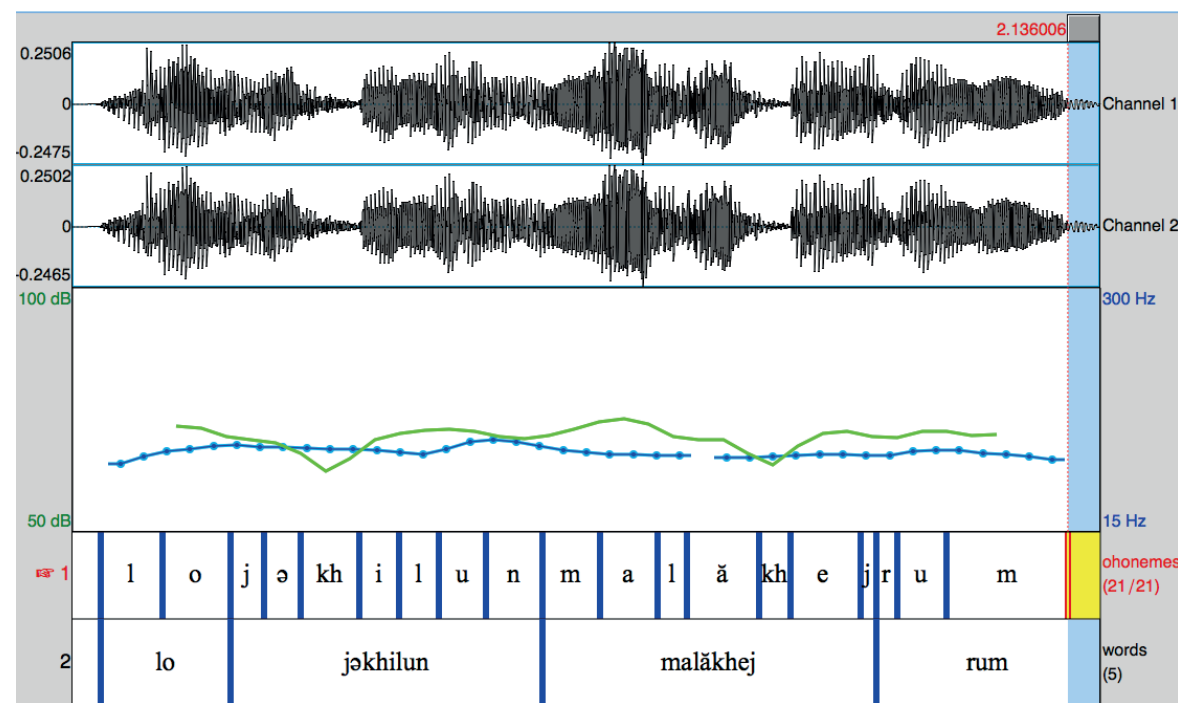

Figure 3. Wave plot, and pitch and intensity contours of "lo? jəkhilun mal?ăkhej rum"

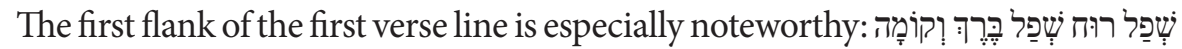
(šəfal ruah, šəfal berekh vəqoma). It consists of three parallel attributes of situation, each coinciding with a metric foot. In the hamarube meter, the last metric foot is foreshortened; accordingly, Ibn Gabirol does not repeat the word "šfal" the third time, supposing that the reader will infer it. From the phonetic point of view, the stressed vowels in the three words "ruah... berckh vəqoma" $(/ u-\varepsilon-a /)$ constitute a falling sequence of high, mid- and low vowels, thus serving as an iconic imitation of falling on one's knees. From the rhythmic point of view, I should have expected the reciter to insert equal pauses between the three parallel units. However, Moš $\operatorname{Hovav}$ observes a pause only after "ruah", and performs "berckh vəqoma" in close succession", harming, in my mind, the rhythmicalness of the performance. He may have assumed that after the deletion of the third "šəfal", he had to group together the two parallel genitive nouns. Listen.

Now listen to the first flank of the third verse line:

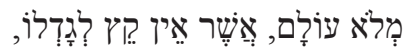

məlo? Solam, جăš̨r Pen qeș ləgodlo 


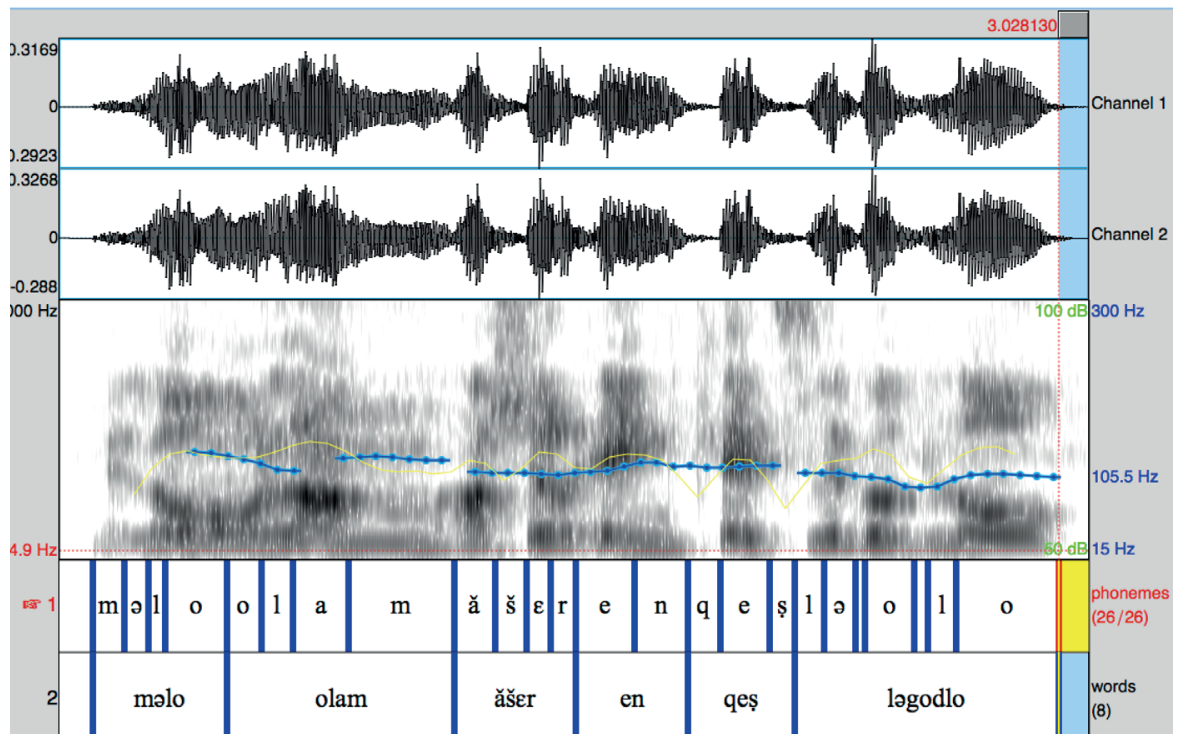

Figure 4. Wave plot, spectrogram, and pitch and intensity contours of məlo? Solam, Pǎšcr Pen qeș ləgodlo

The listening ear may discern some intriguing occurrence at the transition between the words "Yolam, Păšsr". [listen] It hears some lingering at the end of the word "Colam" and a strong drive across this lingering toward the next word. A look at Figure 4 may account for this feeling. There is no measurable pause between these two words. But the consonant $/ \mathrm{m} /$ is the longest phoneme in this flank, almost twice as long as the preceding vowel /a/. This arouses a sense of lack of progression, the end of something. At the same time, the intonation contour creates late peaking: the intonation on this vowel begins at a relatively low pitch, gradually mounting up to its boundary and beyond it, to the beginning of the long nasal consonant $/ \mathrm{m} /$. As we have seen, this phenomenon is perceived, according to gestalt rules, as a source of a forward drive. Thus, we are facing here continuation and discontinuation at the same time. The preceding instances served to solve the problem of incongruity between word boundaries and foot boundaries, whereas here, the word boundary and foot boundary coincide. Here it serves to solve a different problem. The vocative "molo? Solam" (You, who fill the whole Universe) is separated, according to the rules of syntax, from the rest of the sentence. Thus, in this case, discontinuity serves to foreground syntactic separation, whereas continuity - the continuity of the verse line. The performer could fulfill his syntactic obligation by a simple pause between the words; but here he preferred to foreground 
both the unity and the complexity of the verse line (elsewhere I called this "divergent delivery style").

The listening ear may discern similar stopping and forward drive, though more moderate, in the consecutive words "Pen qeș". Here, too, the reasons are similar, partly at least. Consider the consonant cluster /nk/ (in presentday Hebrew, qof is pronounced as a velar consonant). In French, but even in English and Hungarian, it would result in co-articulation of the nasal and velar consonant (both are generated by manipulation of the velum), and the $/ \mathrm{nk} /$ would become nasalization $(/ \mathrm{n} /)$ of the preceding vowel (as in English "think"). In Hebrew, such co-articulation is not possible, so that one must clearly articulate the boundary of the first consonant. This, again, creates discontinuity. At the same time, the intonation contour gradually rises on the vowel /e/, and its peak even "spills over" to the ensuing nasal /n/. This double perception serves here as a solution to an additional problem. The two words "Pen qeș" constitute two consecutive stressed syllables. The performance of this demands clear articulation of the boundary of the first word but, at the same time, continuity is taken care of.

With reference to this flank, one must note an additional issue. In the phonological sequence "məlo? Golam" there is a pharyngeal stop, ayin / / /. In Moš Hovav's performance, I could not discern its pronunciation, or its trace in Figure 4. Distinction between the two tokens of /o/ is suggested by pitch change: on the first token it is more or less sustained, on the second token it is descending. Moreover, the first token is considerably longer, suggesting some discontinuity between the two tokens.

\section{Rav Qorah's Performance}

Now let us turn to a performance of Ibn Gabirol's poem by Rav §Ezra? Qorah, a Yemenite master of "singers of songs". [Listen] As will be remembered, Shirman and Bahat claim that from the Yemenite tradition one may learn about the original authentic performance of the pegs-and-cords meter. I received from Avner Bahat Rav Qorah's first of three recordings of this poem. From listening to this recording, and to recordings of other poems by other singers of songs, I came to the conclusion that this is not at all so unambiguously the case. I wish to make three observations. 1. According to the notes, at least, taken down by Avner Bahat, indeed, in some cases the schwas and their allophones are eighths of a note, or shorter; but in many places they are quarters, not shorter than the adjacent vowels. 
2. As we have seen in the poem under discussion, in some instances, Mošc

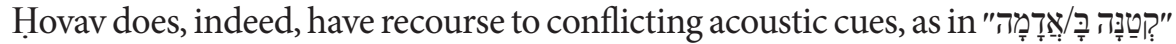
(qətana ba/Pădama). This is one point where Rav Qorah too produces a similar effect, but with different vocal manipulations. Consider the following notes of the flank

kətolaৎat qətana ba?ădama

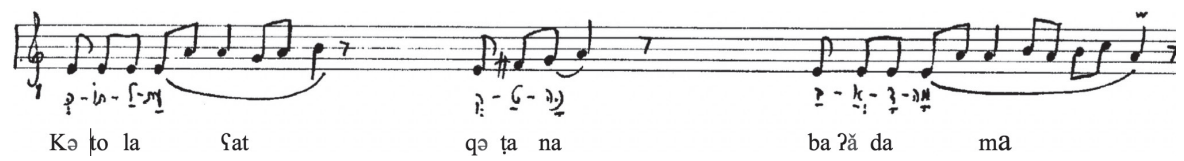

There are three schwas in this flank, all of them are marked as an eighth note, exactly like the ensuing syllable. The word boundaries are indicated by a pause after every word, involving a pause in the middle of the foot /qotana ba-/. However, listening to the sequence "qətana ba?ădama" and a glance at Figure 5 cause a rather complex impression: there is a longish, 0.427799 millisecond-long pause after "qətana", and the "ba-" in "ba?ădama" is perceived as of roughly equal length with /ă/, and does not cue discontinuity. [Listen] As a matter of fact, "-na" is over four times longer than "ba-". This may reinforce the sense of discontinuity aroused by the pause. However, here something most intriguing happens. Close listening may discern some forward drive from the word "qətana", across the pause, toward the syllable "ba-" - generating a sense of end (of a word) and a push to complete the metric foot, at the same time. Not as in the other words, the wavering embellishment at the end of "qətana" does not fade away in infinity, but is perceived as leading across the pause, where it is sharply cut off by the abrupt fall of pitch.

This forward drive will be better discerned if we isolate "-na ba?ăd-". [Listen] A glance at Figure 5 will easily account for this sense of forward drive. Both the intensity contour and the contour of drawn-out wavering embellishment gradually mount all along the syllable "-na” (actually, all along the word "qətana"). In fact, the computer output shows a much longer and more complex wavering embellishment than the notes, suddenly cut off by the abrupt fall of pitch. With the transition to the word "barădama", there is a sudden fall. As we have seen, mounting intensity and late peaking of intonation may generate a sense of forward drive. Here the mounting pitch contour constitutes a very late peak. There is also a late peak in the last vowel of "ba?ădama" which, with the sudden rise of intensity at the very end are definitely experienced as a forward push into nothingness. 


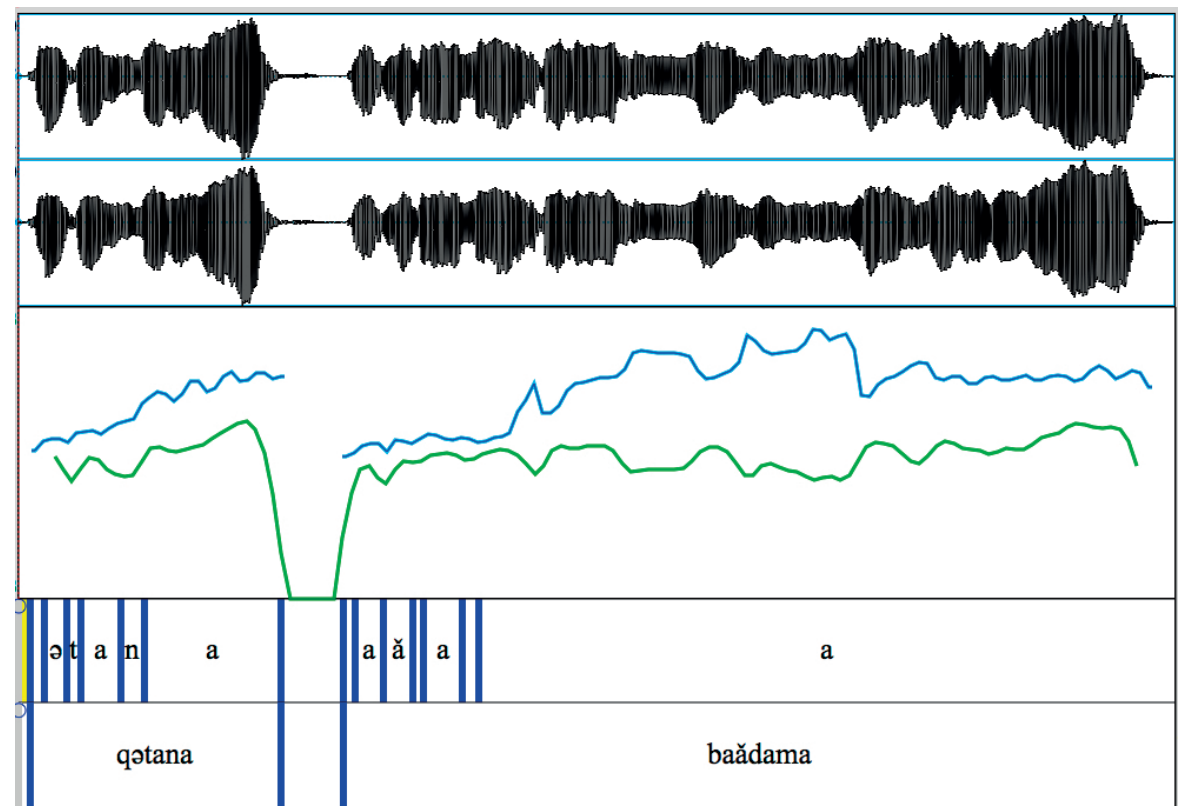

Figure 5. Wave plot, and pitch and intensity contours of "qətana baPădama", performed by Rav Qorah

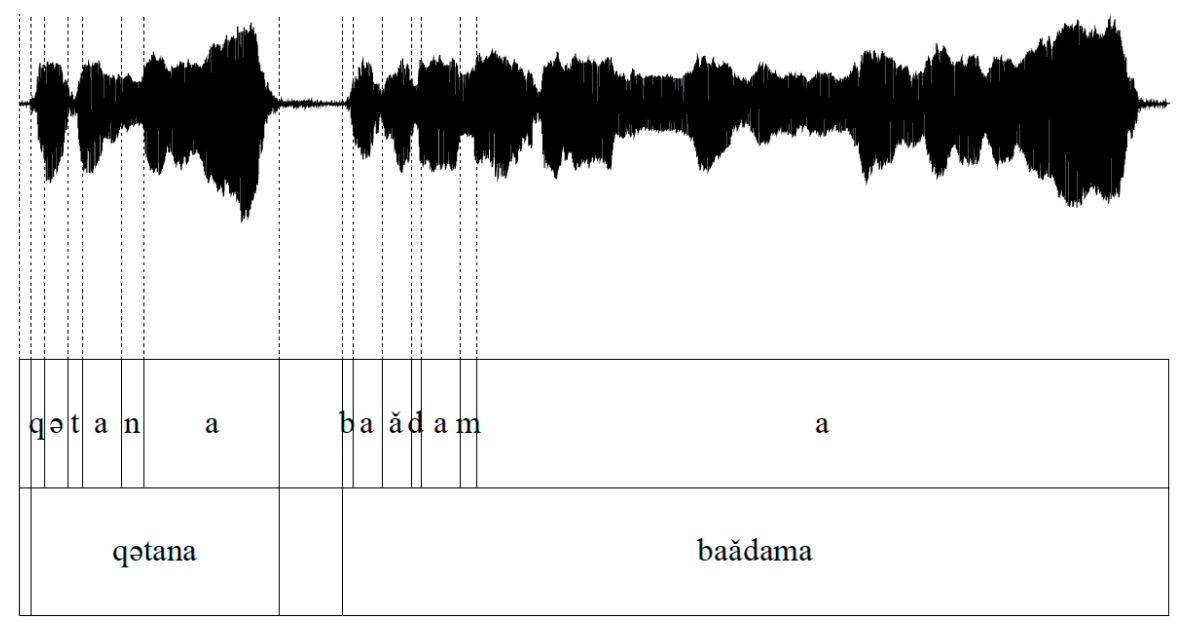


Now such an abrupt fall is not to be taken for granted in the present performance. Gestaltists speak of closure in music and visual perception. Barbara Herrnstein Smith applied this principle to poetry in her brilliant book Poetic Closure. Closure is the point where uncertainty disappears. Herrnstein Smith distinguishes at the end of poems between mere cessation, and proper cessation, that is, closure - a sense of finality, a sense that nothing more is to be expected, a sense that everything that preceded leads up to this point. In Western music, the melodic line contributes to closure by falling to the tonic. Herrnstein Smith also speaks in poetry (and Leonard B. Meyer [1963] in modern music) of "anti-closure", where closure is effected, but sabotaged by some stylistic device indicating continuity. In Rav Qorah's performance the abrupt fall at the boundary of "qətana" is an exception. Consider the three word boundaries in this flank; all are marked by drawn-out wavering embellishments, ending on a relatively high note - fading away in infinity, as it were. This tendency is quite typical of Rav Qorah's performance. However, not as in the other word boundaries, the mounting melodic line on "qətana", far from fading away in infinity, abruptly ends and falls. It would appear that two factors make the difference: after "qətana", the wavering embellishment is shorter than the other two, and occurs in mid-foot. Note that the last syllable of the line, "-ma" is long beyond any proportion, suggesting discontinuity, whereas the exceptionally long wavering ends on a high note, suggesting continuity. Such a combination typically generates anti-closure - fading away in infinity. We cannot know how Mediaeval Hebrew poets sung their liturgic poems; but, in my 1969 book, long before I was exposed to Barbara Herrnstein Smith's work and its gestalt principles, I had pointed out that in their written texts, eleventh-century Hebrew poets made conspicuous efforts to generate effective closures at the end of their liturgic poems, and also at line-endings (I did not call it closure, but "a sense of finality").

Some of the broader aspects and implications of anti-closure have been suggested by Leonard B. Meyer in an article published in 1963 in which he distinguishes traditional and contemporary music. The latter, he writes, "directs us toward no points of culmination, establishes no goals toward which to move." (p. 174). The philosophy of the new aesthetics is summarized by Meyer as follows: "The denial of the reality of relationships and the relevance of purpose, the belief that only individual sensation and not the connection between them are real and the assertion that predictions and goals depend not upon an order existing in nature, but upon the accumulated habits and preconceptions of men - all these rest upon a less explicit but even more fundamental denial: a denial of the reality of cause and effect" (ibid.: 178). Briefly, I would say, it is an aesthetics of disorientation. 
One might cautiously speculate that in Rav Qorah's case, anti-closure has a different character. The boundaries and their suspension are perceived differently in the two contexts. In traditional Western music, closure is perceived as a point toward which everything in the work strives; the elimination of clearcut boundaries in avant-garde music is perceived as the abolishment of goals toward which to strive. Rav Qorah's drawn-out embellishments, by contrast, arouse a vague intuition of some reality beyond the Ultimate Limit. In other words, sounds and perceived effects cannot suggest specific meanings, only some vague psychological atmosphere, in this case an atmosphere of lack of definite direction, lack of control and patent purpose, that can be individuated by the context either as disorientation, or the vague intuition of a reality that inspires uncertainty, because inaccessible to the senses or the intellect. To be sure, drawn-out embellishments are characteristic of music of the Arab cultural sphere in general; but here the contents realizes their limit-blurring feature. In all my writings I conceive of all sound structures as multivalent: every structure may be exploited for a variety of effects by the context. The indicative is used in interpretation not to state facts, but to suggest what is plausible (and, logically, what is plausible its opposite is plausible as well, as with the interpretation of anti-closure [see Margolis 1962]).

3. The first two observations refer to one specific performance, though one may discern similar phenomena in other performances of other poems as well. My third conclusion is of a more cardinal nature, and is pessimistic regarding the possibility to learn at all about the real nature of poetic rhythm from sung performances, where repetition of phrases and drawn-out embellishments are involved. So far we have seen two variables of poetic rhythm: regular alternation of short and long units that, in principle, could endlessly be repeated; and an elegant solution of problems arising from incongruity of word boundaries and metrical foot boundaries. But there is a third variable too, no less important. Versification of the pegs-and-cords meter, as other meters, is hierarchical: the verse line divides into flanks, the flanks divide into metric feet, whereas the feet divide into schwas and vowels. From the perceptual point of view, the units divided are no less important than the dividing units; as a matter of fact, rhythm arises when the sequence of alternating schwas and vowels is simultaneously perceived with the flank. In order for the flank to be perceived as a whole unit, it must not exceed the span of short-term memory. It seems that poets of all generations in Western culture, from classical Greek poetry to our days, including the Hebrew poets in Spain, observed this principle. ${ }^{7}$

7 Greek prosody scholar Steven Willett challenged this position of mine (2001), claiming that 
Here enter the limitations of short-term memory. Consider, again, Rav Qorah’s performance of the flank

kətolaSat qətana barădama

It is parsed into three units by word boundaries, with an audible pause between them. The boundaries of the words "kətolaYat" and "Pădama" coincide with foot boundaries (the latter with the line boundary too. These boundaries, however do not articulate the flanks into clear-cut perceptual units, In this respect, the sabotage of closure at the line boundary is crucial. Also, significantly, these drawn-out wavering embellishments may exceed the span of short-term memory. In this version, Rav Qorah repeats the entire first flank, "šəfal ruah, šəfal berckh vəqoma”. In this case, the repetition per se does no harm to poetic rhythm, because it does not interfere with the perceptual integrity of the flank.

In his other two performances, however, repetition does interfere with the integrity of the flank. In his third recording, for instance, he repeats the foot "šəfal ruah" alone, so that the listener loses sight of the whole flank, or the whole verse line as a unit contained by short-term memory. This is legitimate from the musical point of view. But by this he violates the structure of the flank from the prosodic point of view, so that it exceeds the span of shortterm memory. We may willingly suspend our objection to the change of the poem's words; but we have no volitional control over containing the excessive length within the span of short-term memory, that is essential for perceiving the flank as a rhythmic unit.

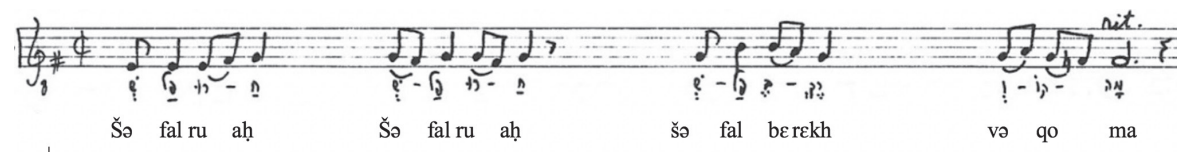

Greek poetry refutes the existence of the limitation I am arguing for. His argument was that in Greek poetry, on paper, there are much longer units of versification. The paper seems to be more tolerant than short-term memory. But in less than two years, Willett publicly withdrew his criticism. He expounded the change of his mind in the same journal (Willett 2005). As it turned out, there was a major revaluation in the field, with no connection to my research. Scholars of Greek versification accepted, at long last, the position of a group of scholars in Alexandria toward the end of the third century $\mathrm{BC}$, who divided the controversial poems in a way that conformed with the psychological principles I have proposed. 


\section{Digression on Jewish Baroque Music}

I have said that no recordings or musical notations have been left from the authentic pegs-and-cords tradition ${ }^{8}$. This state of affairs has now changed, thanks to the pioneering work of Professors Israel Adler and Edwin Seroussi, musicologists. Recently, the Jerusalem Baroque Orchestra, directed by David Shemer, gave a concert of Jewish Baroque music, based on their findings. In the seventeenth and eighteenth centuries, when the pegs-and-cords tradition was still alive and kicking, there were Hebrew musicians who worked within the Baroque tradition, and left scores of some fine music in the best Baroque tradition. Some of the texts were in the pegs-and-cords meter.

One of the works set to music is the first two verses of the widespread liturgic text "ădon olam" (Lord of the world) by an anonymous poet, sometimes attributed to Ibn Gabirol. The music, too, is by an anonymous 18th-century composer (perhaps, compiler).

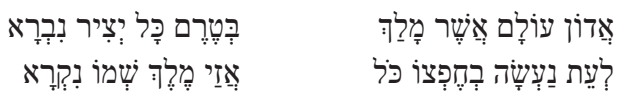

Pădon Solam Păšer malakh bəterem kol yəșir nivra?

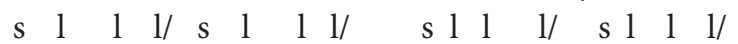

ləSet naৎsa bəḥ̂fșo kol Tăzaj melekh šəmo nikra?

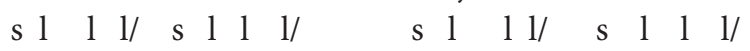

The letters $s$ and $l$ under the text indicate "short" and "long"; the slashes indicate foot boundaries.

Lord of the world who had ruled when everything was made by his will before any creature was created then His name was called King

The present section is merely a pilot study, focused on the first two words, with some reference to the whole. The versification of this poem is somewhat exceptional, though well within the tradition. The verse line consists of two flanks, but each flank consists of only two hamarube feet. The poem as a whole contains a virtuoso mono-rhyme running through thirteen verses, and displays some other conspicuous structural complexities that generate tension followed by relaxation in a rigorously controlled manner (which, alas, cannot be discussed here). In these two lines, each foot boundary coincides with a

${ }^{8}$ I wish to thank Idith Shemer from the Jerusalem Baroque orchestra for her generous help. 
word boundary (though, once in mid-phrase); in other words, foot boundaries do not conflict with word boundaries. In spite of this lack of complexity, it is illuminating to observe how the music confirms the present structuralist conception of poetic rhythm. While the schwas are consistently shorter than the vowels, the vowels observe no equal or proportional time periods. Poetic rhythm is secured by mapping of the sound patterns on an abstract metric pattern, clearly articulating word and foot boundaries.

As to the written scores, they have here a very different status from those we found in relation to Rav Qorah's performance. In the latter case, a modern musicologist took down what he heard in a present-day performance by a performer who followed an oral tradition. In the former case, an eighteenthcentury composer wrote the music in accordance with how he understood the pegs-and-cords meter prevalent in his age; in the recorded music we hear how present-day performers interpret the written score. In the score, the contrast between the schwa and full syllables is 1:2 or 1:3 (as suggested by Schirman); in the recorded music it is usually much greater. Briefly, in the case of "ădon olam" the score came first, the performance last; in Rav Qorah's case, the performance came first, the written score last. In the score of "ădon olam" we have, then, written evidence of the rhythmic competence of at least one eighteenth-century musician (but with modern orchestration).

In Figure 6, the initial /ă/ is exceptionally short as compared to the ensuing syllables (even though the performer sounded here an additional/d/). The ensuing speech sounds are very long and of conspicuously unequal duration. This, however, does not seem, for some reason, to sabotage the rhythmic character of the text. This is, because the composer imposes on the text the gestalt dynamics of expectation-and-satisfaction, generating an exceptionally clearcut foot boundary. The phonemes of varying duration appear chaotic at first sight, but their sequence is sharply cut off by the foot boundary. According to the structuralist conception, poetic meter is not based on equal or proportional timing, but on expectations and fulfillment in mapping the sound patterns on the abstract metric patterns. Here there is an additional restriction: the Schwa must be shorter than the full vowels. 


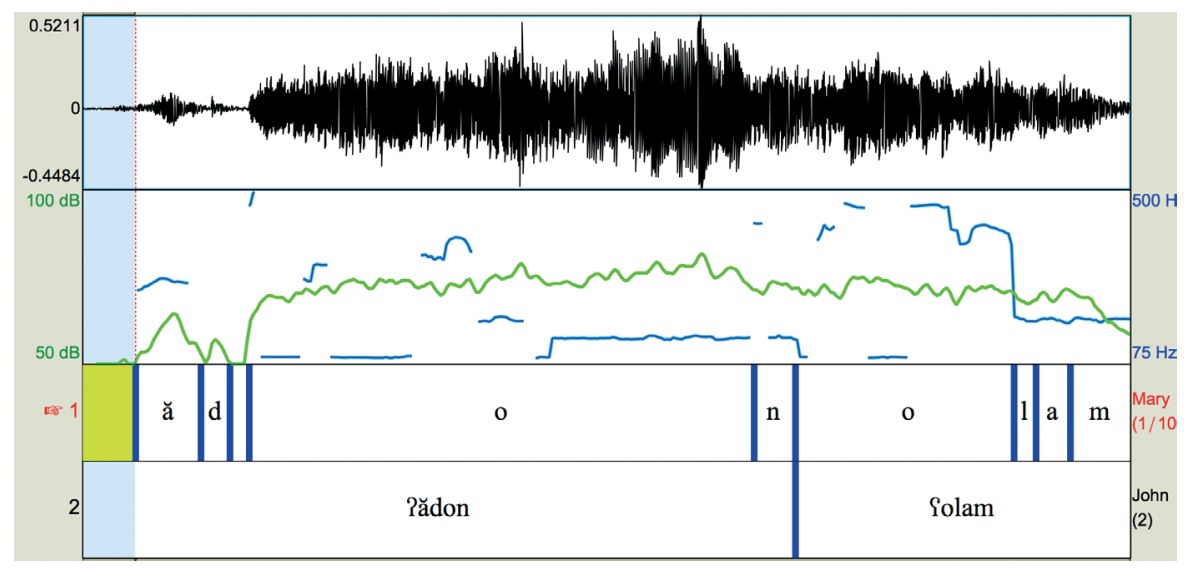

Figure 6. Wave Form, F0 contour and intensity curve of "ădon olam" in the performance of the Jerusalem Baroque orchestra. [listen to the first two words]

Thus, instead of generating chaos, the phonemes of irregular duration press against the forceful closure of the foot, generating tension. The melodic line follows certain principles of the intonation contours we have pointed out in poetry recital. A longish rising melodic contour on "ădon" ends in an exceptionally late peak on the $/ \mathrm{n} /$. Note that the rich orchestration has confused the computer application. The sustained low F0 on the second half of /o/ and on $/ \mathrm{n} /$ indicates the dominant $\mathrm{F} 0$ of the orchestral music; the intonation peak of the singer is indicated only by a minute curve-segment over $/ \mathrm{n} /$, while a substantial part of the preceding mounting intonation curve is missing; we can only hear this rising sequence, and see where it ends. At any rate, the mounting "intonation" contour with its late peak exerts a powerful perceptual forward push leading to a slightly mounting and sharply falling intonation curve on /o/, followed by a sustained low contour on /lam/, indicating lack of progress, firmly closing the foot. Briefly, the melodic line strongly reinforces the closural potential of the coinciding word and foot boundaries. 
[2] אדון עולם [Adôn 'ôlam]
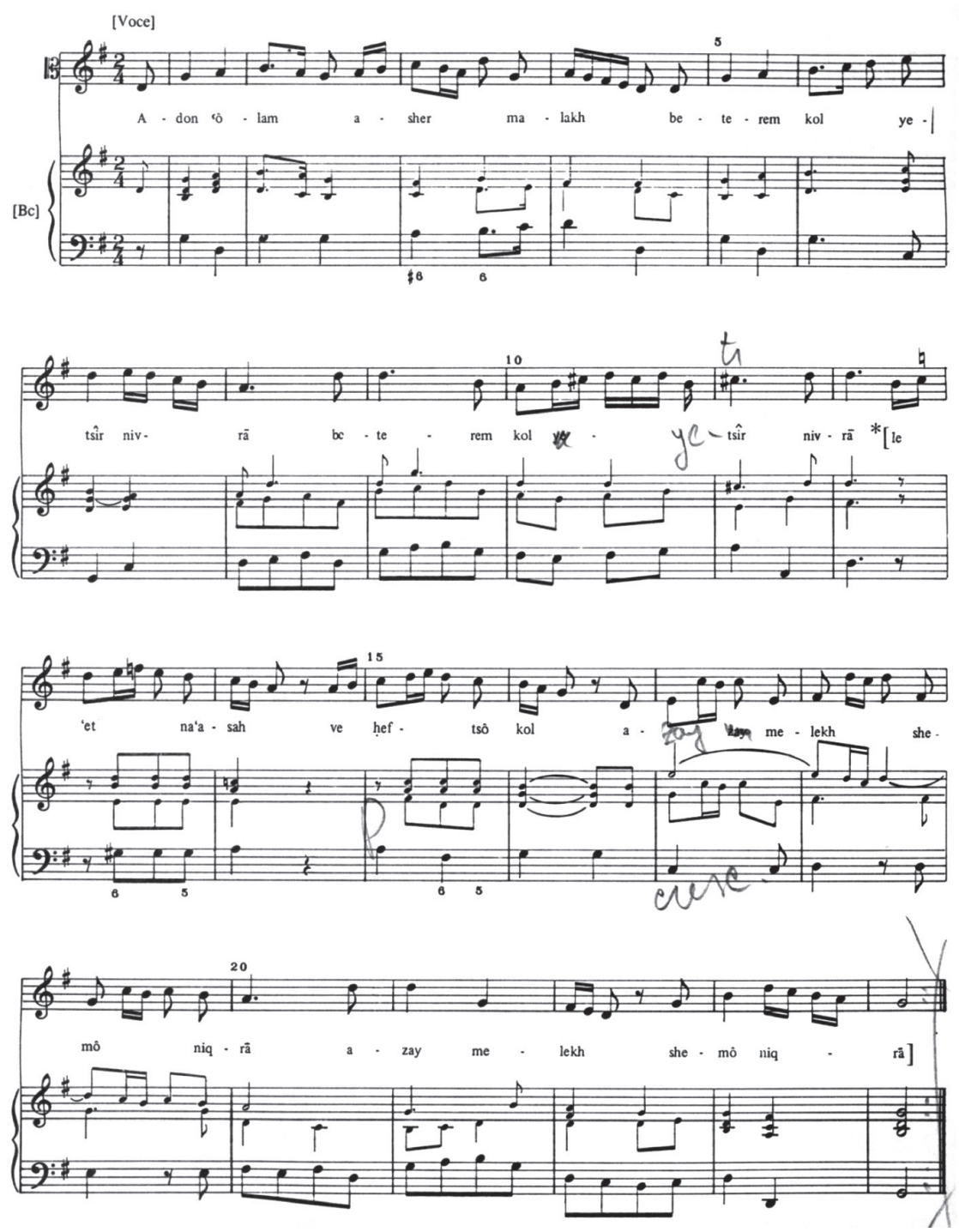

Figure 7. Score of the voice part of "ădon olam".

The present view of poetic rhythm does not espouse a simplistic conception of proportional timing even in quantitative meter. A structuralist approach is preoccupied with the correspondence of the linguistic and versification patterns, whose occasional irregularities are accommodated in a performance so that at certain crucial points linguistic and versification units have coinciding 
downbeats or boundaries, emphatically restoring regularity. The greater the irregularities and the stronger the reinstatement of regularity, the greater the tension perceived in rhythm and the resulting satisfaction. When irregularities override the reinstatement of regularity, chaos sets in. In the phrase "ădon olam" the closural force of the coincident word and foot boundaries is strongly reinforced by the falling melodic line.

It is illuminating to compare, from the structuralist point of view, Rav Qorah's and the baroque composer's attitude toward the music's relationship to the underlying meter. Regarding the schwa (or its allophones), as we have seen, Rav Qorah is not strict on the time relationship between the schwa and the syllables. The anonymous baroque composer, by contrast, strictly observes in his written score the 1:2 and 1:3 proportion recommended by Schirman.

Regarding foot boundaries, the anonymous composer sharply articulates them, whereas Rav Qorah tends to blur them by drawn-out embellishments. Regarding repetition, both Rav Qorah in his first recording and the anonymous composer in "ădon olam" repeat whole flanks [listen to the first flank repeated in "ădon olam"], so that each token of the flank need not exceed the span of short-term memory. In his later recordings, Rav Qorah repeats parts of flanks, causing the whole flanks to exceed the span of short-term memory.

Mediaeval poets were very particular about poetic meter, and literary scholars (as well as educated readers) set great store by it throughout the ages. Schirman criticised traditional scholarship for having an "optical" approach to meter, as marked on the page. He insisted that one should explore also what one hears. The present work set out to do just that. Schirman was mainly interested in the relative duration of long and short units, and in preserving linguistic stress in spite of the dominant quantitative meter. The present structuralist-cognitive approach also focuses on how intonation (or the music) articulates or fails to articulate meter. It conceives of poetic rhythm as a multi-level structure and treats it on a more fine-grained level. Rav Qorah does not insist on the time proportions suggested by Schirman between schwas and vowels; he also "sabotages" closure at quite a few word boundaries and, by the same token, of some foot and line boundaries, through drawn-out wavering embellishments. He does not articulate versification units (feet, flanks, lines) by emphatic closure; on the contrary rather, he tends to open them up. The anonymous baroque composer's score, by contrast, conforms, to a considerable extent, with the present structuralist-cognitive conception.

The difference between the two actualizations seems to be quite consistent. The text of "ădon olam" begins with an allophone of schwa (ă); the corresponding baroque music begins with a pickup note before the first music bar; all the ensuing (initial) schwas are pickup notes at the end of the bar containing the preceding foot. This is in conformity with the rules of pickup notes, namely, 
if there is a pickup measure at the beginning, the final measure of the piece should be shortened by the length of the pickup measure. In other words, the end of every metric foot leaves room for a pickup note to mark the next initial schwa. A pickup measure is a shorter than usual measure before the first full measure. Musicologists speak of pickup notes as "leading" toward the first note of the next bar; some of them treat it as the last beat of a nonexistent sequence. Some others claim that it "is a common means of weighting the first beat, and thus strengthening or articulating the meter" (Yaraman 2002: 25-27). In terms of the present article, it is a brief unit before the bar boundary, exerting perceptual pressure toward it and beyond. According to the gestalt rules, the boundary intruding in the melodic or verbal units causes them to resist intrusion and to enhance themselves in the listener's perception.

Judging from the notes taken down by Bahat, there are no such pickup notes in Rav Qorah's performance - the schwas have a more leisurely relation to the ensuing syllables. We have seen that poets of the time regarded the peg (schwa + vowel) as one long unit and the cord (a vowel) as a short unit. Schirman, by contrast, proposed, for the sake of scientific parsimony, to treat initial schwas as short, and all the rest as long. He regarded this as a technical, not aesthetic issue. For the same technical reasons, he too marked schwas in his notation of the hamarube meter as pickup notes. According to our foregoing analysis, the pickup note may be interpreted here as pushing toward the next note, generating a unit of two, more closely related than the other vowels. We shall be able to say more about this when we find a baroque music setting of a text in whose meter schwa comes before the last syllable of the metric foot.

There are good reasons to suppose that the baroque composer conceived of this as an aesthetic issue. He exerts control over the metric foot, conferring on it definite direction through the pickup note, the late peak and the falling melodic curve (the foot pushes toward its boundary, where it is cut off). Whatever the liturgic conception of the place of poetic meter in the whole, literary people of the past few centuries lay great store by it; and this seems to us to be the attitude of eleventh-century poets too. The pickup note has, in the above sense, an organizing function for the metric pattern, imposing a direction on it. The interaction with the melodic line clearly articulates foot boundaries and flank boundaries, generating a dynamic of anticipations-andfulfillments. Rav Qorah, by contrast, places the schwa at the beginning of the bar, and blurs boundaries by drawn-out embellishments. He also causes flanks to exceed the span of short-term memory, by drawn-out embellishments and/ or repeating part of the flanks.

These are not to be regarded as mere success or failure to realize the rhythm of the pegs-and-cords poetry. They must be regarded as two different, consistent 
aesthetic conceptions. Applying here one of Meyer's brilliant insights outrageously out of context, closure "creates a psychological atmosphere of certainty, security, and patent purpose, in which the listener feels a sense of control and power as well as a sense of specific tendency and definite direction" (Meyer 1956: 160). Anti-closure generates an opposite kind of psychological atmosphere of uncertainty. As we have seen, the psychological atmosphere generated by anti-closure may be individuated in as disparate experiences as emotional disorientation and a transcendental orientation. Rav Qorah's attitude in performing Ibn Gabirol's devotional poem is certainly the latter. The eighteenth-century baroque composer, by contrast, applies, systematically, emphatic closure to versification boundaries. Here this has not, necessarily, a rationalist function (as a symmetric opposition to the transcendental function of anti-closure in Rav Qorah's performance). It rather suggests strict aesthetic organisation; baroque music expresses yearning for the infinite by different means (that are beyond the scope of the present article). In other words, the human mind, in its quest for consistency, picks out different aesthetic potentials of stylistic devices within their respective wholes, in this case of closure and anti-closure.

We do not have, however, independent grounds for preferring one of the two conceptions to the other, except on circumstantial evidence: in the baroque version, an essentially Oriental tradition has been influenced by a Western tradition. What I have done in the foregoing is to offer some tools to describe them on a more fine-grained level, so that we better understand what it is that they disagree about. ${ }^{9}$

\section{Can "Pegs" have Psychological Reality?}

My article adopted two of Schirman's assumptions as its starting point. First, the overwhelming majority of works on Mediaeval meter was engaged in optic marking of the metric feet on paper and in the poets' grammatical knowledge. However, Schirman says, it is time to inquire into rhythm as an auditory experience, what in the generative terminology might be called the poets' intuitive

9 In an article on meter and melody in Yemenite liturgic poetry by a linguist and a musicologist, Shlomo Morag and Amnon Shiloakh make an intriguing observation: that Yemenite masters stress the vowel following the schwa in a peg, even if it bears no linguistic stress (p. 443). They provide no sound files, and even no relevant musical notes; so, I could not test it. But, if substantiated, a fascinating possibility suggests itself. If no acoustic cues for stress are involved, then it may be the dynamics discussed with relation to pick-up notes that foreground the syllable as stressed. 
knowledge, and the psychological reality of the meters. In all other matters of research, Schirman was a militant factualist: but when it came to poetic rhythm, he couldn't resist going beyond the plain facts on paper.

Secondly, according to the assumptions of gestalt theory, the perceived musicality of poetry is not based on the knowledge of complex rules, but on the simplest perceptual organization that the prevailing conditions permit. Schirman, who objected to the application of modern psychological or poetic theories to Mediaeval poetry, simplified, nevertheless, the system, for practical reasons. Perhaps, he followed intuitively Occam's principle. He proposed that for an understanding of the system of classical meters one needs to distinguish only two elements: schwa mobile (or its allophones) and full vowels. For the purpose of synchronic discussion, all the other distinctions regarding vowels may only obscure the scheme - the distinction between vowels followed by a consonant, vowels followed by one of the matres lectionis (aleph, he, vav, yud), or by both a consonant and a mater lectionis. Schirman's conception further implies that it is simpler to regard e.g. the hamarube metric foot as consisting of a schwa plus three vowels than as a peg (which, in turn, divides into a schwa plus vowel) plus two vowels.

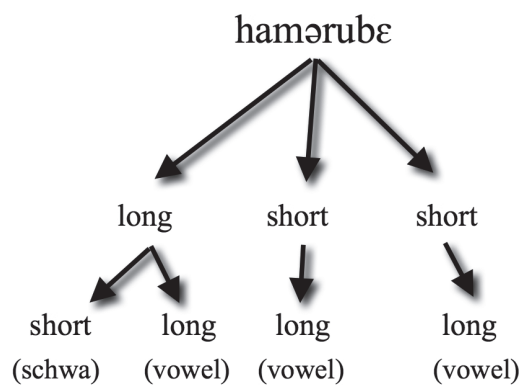

Figure 8. Generative tree representing hamərube foot as a peg and two vowels

Figure 8 represents, in a generative tree, the Mediaeval poets' and grammarian's conception of the hamarube metric foot. This is a hierarchic conception, according to which the foot is divided into a long and two short units in which, in turn, the first, long unit is further divided into a short and a long unit. Schirman's conception is represented by the "tree" in Figure 9. This conception acknowledges only the immediately-observable constituents. Thus, the hamarube metric foot is divided into one short unit (schwa), and three long units (vowels). What is at stake here is the issue of psychological reality (in terms of generative linguistics). Generative linguists have pointed out that the grammatical rules in traditional grammar books are not necessarily the ones 
that govern the cognitive system when flesh-and-blood humans use language. In our case, the paper is, doubtless, very tolerant, and tolerates the grouping of two immediately-observable units into one abstract category. The question is whether one can experience the word "אָָָּר" (?ăval Hebrew for "but") as one long unit (peg), or as a shorter plus a longer unit. Simple introspection would suggest that one experiences the sequence as two units. However, generative linguistics assumes that theoretical units too, not only immediately-observable ones, may have psychological reality. This issue, the psychological reality of theoretical entities, has been extensively researched during the past few decades, in the psycholinguistic laboratory (see, for instance, Fodor and Bever 1965; Garrett, Bever, Fodor 1966; see Appendix).

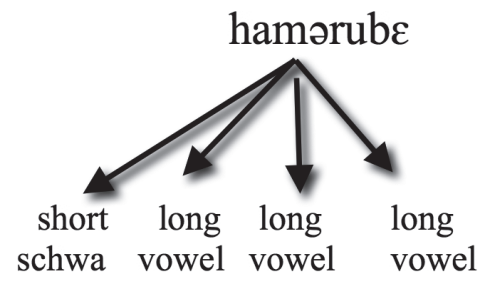

Figure 9. Generative tree representing hamərube foot as a schwa and three vowels.

No recordings of poetry readings have been preserved from the eleventh century. Fodor et al's experiments provide conclusive evidence that even where all possible influence of acoustic cues is eliminated, the perceptual boundaries of theoretical entities may definitely affect listeners' perceptions. So, too, one may not dismiss lightly the possibility that pegs in Mediaeval meter did have psychological reality for some poets and readers. Since, however, we have neither recordings nor detailed descriptions, our research resources are severely limited. In this state of affairs, we cannot hope to test by Fodor et al.type experiments perceptual effects triggered by mental representations that are not associated with manipulable acoustic correlates. But the performance of English syllabotonic poetry by present-day reciters offers an illuminating precedent, with manipulable acoustic correlates. This would suggest that there is a possibility that in some vocal or mental performance Ibn Gabirol's readers could experience the word "ăval" as one abstract entity. There is convincing evidence that two consecutive syllables can be perceived, in a rhythmic hierarchy, as one or two theoretical entitie(s), as may be required by the verse structure. In English syllabotonic verse there is a phenomenon called by generative metrists "disyllabic occupancy of metrical position" (in Shakespeare's "Anthony and Cleopatra", for example, such instances of disyllabic occupancy abound). Generative linguists have even determined the phonetic conditions 
in which two syllables may be squeezed into one metric position. One of the conditions is that the syllables contain two consecutive vowels, with no consonant between them, irrespective of word boundary, or contain liquids or nasals $(/ \mathrm{l}, \mathrm{m}, \mathrm{n}, \mathrm{r} /$ ), or $/ \mathrm{h} /$, or glides /j, w/ or, from the seventeenth century on, voiced fricatives (see Halle and Keyser 1966: 209; Freeman 1969: 197 -198). In my book Poetic Rhythm: Structure and Performance - An Empirical Study in Cognitive Poetics I devoted a whole chapter to a theoretical discussion of this phenomenon and its instrumental investigation (2012: 267-294). We are facing, then, a most paradoxical problem: two immediately-observable units are said to be perceived at some invisible and inaudible level as a single perceptual unit. An inquiry into the nature of such paradoxical perception requires, as will be seen, detailed description of its vocal performance.

At the theoretical level, I asked what is the common feature to all the foregoing conditions. The answer I found was that the boundary between the two syllables squeezed into one metrical position is not abrupt as in voiceless plosive. All eligible consonants are continuous, and all but one (/h/) voiced. In English poetry there is a convention that certain disyllabics, as "even, ever, heaven, seven, power, tower, spirit, devil, evil" etc. are squeezed into one metric position. The second vowel in these words is reduced which, in some editions, are replaced by an apostrophe. Some of those words, "heav'n", for instance, cannot be pronounced at all as one syllable, even if the editor substituted an apostrophe for the reduced vowel on the paper. All these words conform with the rules put down by generative metrists. The same goes for the phrase "many a" that very frequently occupies only two positions. In my instrumental research, I traced the vocal manipulations that yield satisfactory results. Consider the following two lines:

May be the devil; and the devil hath power

To assume a pleasing shape; yea, and perhaps

(Hamlet II. ii.)

In the first line, the word "power" is stressed on its penultimate syllable; the syllable following the last stressed syllable of the line is "extrametric" in the iambic meter (this is allowable and widespread at line endings in all the languages known to me). Before the last stressed syllable, there are eleven syllables, but only ten metrical positions available. Presumably, somewhere, two syllables must be assigned to one metrical position. The same goes for the second line. I have marked in these two lines the pairs of syllables that are eligible for disyllabic occupancy, according to Halle and Keyser' conditions. 
In the first line, various performers may choose different solutions. In the second line, the two syllables destined for squeezing are "to ass-", even though they belong to different words. It seems that listeners can discern, with considerable accuracy, where are two syllables assigned to one metrical position. And instrumental research can show, by what vocal manipulations has this been achieved. Of the possible vocal devices I propose to point out only one, the most typical one. In my said book I have shown that when the matching between the stress pattern and metric pattern is upset by a stressed syllable in a weak position, experienced performers tend to foreground the metric pattern (that is not immediately observable) by over-articulating the syllable boundaries. In case of disyllabic occupancy of one metrical position, we find frequently over-articulation of the syllable boundary that coincides with the position boundary, and under-articulation of the boundary between the syllables within the position. This may foreground the two syllables in one position as a unit.

It makes little difference whether line-final "power" in the above excerpt occupies one or two positions. Some performers perform it in one, some in the other way. Figure 10 shows the amplitude envelop in three performances of the word "power" in a poetic context. In the first on the left it is perceived as a word whose two syllables are assigned to separate positions; the other two are perceived, each, as words whose two syllables are squeezed into one position. The two markers mark the boundaries of the glide [w]. Figure 8 shows two relevant differences in the amplitude envelop of the three tokens of the word. First, in the leftmost token there is a "valley" in the amplitude envelop, foregrounding the division of the word into two syllables, whereas in the other two tokens there is no such a "valley". Second, the glide [w] (whose boundaries are marked by the markers) is longer in the leftmost token than in the other two. These two devices are perceived only subliminally, but the articulation of the boundary between the two syllables is perceived as more clear-cut in the leftmost token than in the other ones. 


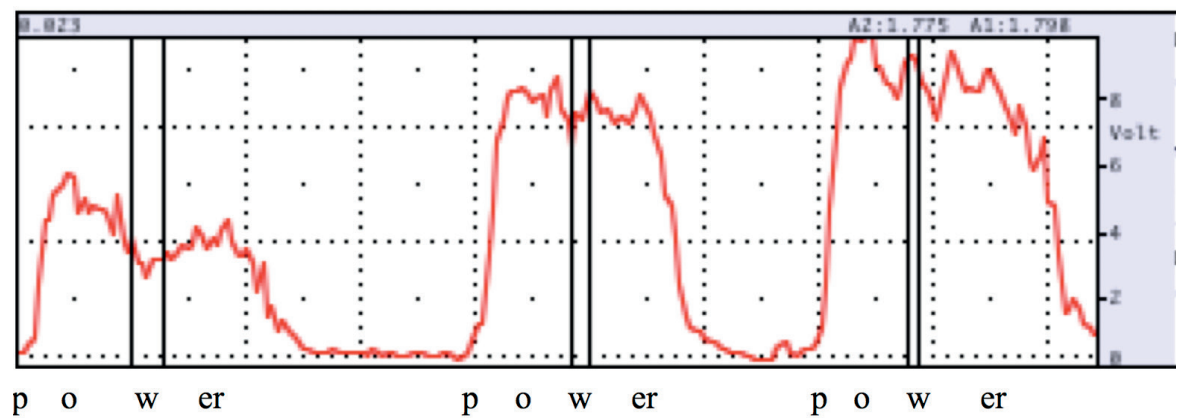

Figure 10. Amplitude envelops of three tokens of power in poetic context. The leftmost token is perceived as one-to-one matches between syllables and metrical positions; the other ones as disyllabic occupancy of one metrical position.

[Listen to three tokens of "power", excised from DF's three readings of the Hamlet excerpt].

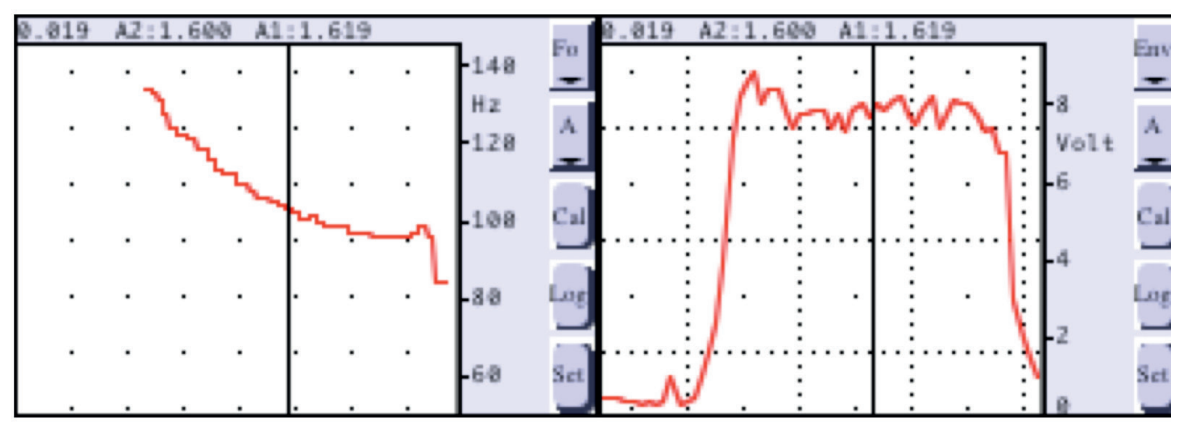

Figure 11. Intonation contour and amplitude envelop of a fourth token of the word power in poetic context. The flat amplitude envelop reduces the articulation within the position; the terminal intonation contour increases articulation at the position boundary.

[Listen to "power", excised from DF's reading of Milton's "Him the Almighty power/ Hurled headlong flaming from thethereal sky"].

Of the many devices for over-articulating the position boundary, I will mention only falling (terminal) intonation. Figure 9 shows a fourth token of the word type power in a poetic context. The fairly flat amplitude envelop is responsible for underarticulation within the metrical position; the falling intonation contour - for over-articulating the position boundary (which, by the same token, over-articulates the line ending in an enjambment). 
A more detailed discussion of this phenomenon can be found in my book. I don't presume that this is how poets of the eleventh century performed the pegs. My purpose in the foregoing analysis was more modest: to demonstrate that theoretically, at least, there is a possibility to perform the hamarube meter in a way in which Figure 8 has psychological reality, that is, that the two immediately-observable syllables (the shorter and the longer one) of the peg can be perceived as one long category on a more abstract level. The peg in mediaeval meter and the metrical position in syllabotonic meter are akin in that both are conveyed by the same noises as the words; thus, the words are immediately observable, the peg and the metrical position are not.

This is the best I can offer in the present state of the art to test the psychological reality of the peg: to demonstrate that it is possible to perform two immediately-observable constituents as suggesting one abstract category. In order to be able to make some more specific claims about pegs and cords, one must find at least two alternative performances, one in which an immediately-observable schwa plus a full vowel suggest a unified abstract category, that cannot directly be perceived, and one performance in which they do not suggest such an abstract category - and see the different underlying acoustic structures. I have not been convinced that performances of the Yemenite masters qualify for such an experiment.

\section{To conclude}

We know nothing about how mediaeval poetry was performed at the time. What we know is that mediaeval poets were very much aware of the problem of congruence and incongruence between linguistic and versification units. This issue is conspicuous whether the verse is spoken or sung; whether the pegs-and-cords meter is performed in the way suggested by Schirman or pronounced so as to conform with modern speech. The aim of this paper was to explore whether there is a possibility to perform these poems in a way that is compatible with spoken language, yet preserve the warring identity of the linguistic and versification units. For this end I used one poem by Šəlomo Ibn Gabirol, read by Mošc Hovav. I have found that from the point of view of rhythmic solution this reading is not of an even level. At some points it offers brilliant solutions, at others it conspicuously ignores the problem. At any rate, it provided evidence that it is possible to perform the linguistic stream and the metric stream so that each may preserve its warring identity. 
Schirman and Bahat claim that the authentic performance of schwas and vowels in the pegs-and-cords meter has been preserved in the Yemenite masters' liturgical songs. My instrumental investigation of a performance by one of those masters found little support for this claim, though I found at least one instance of indicating by vocal means the conflict between word ending and foot ending. In a wider perspective, I have argued that poetic rhythm crucially depends on containing a wider unit within the span of short-term memory, while dividing it by smaller units. Repetition of phrases and the sustained embellishments in the sung versions cause the wider units exceed the span of short-term memory. Thus, in such sung versions it is impossible to preserve poetic rhythm. Then I adduced a brief pilot study of 17th-18th century Baroque settings of Hebrew liturgical poetry, exploring how it handles the pegs-and-cords meter. By the same token, I compared the aesthetic conceptions of the Yemenite master and the baroque composer.

The last section of this article was a modest contribution to the knotty problem of "psychological reality". Eleventh century poets thought of their meter in terms of pegs and cords. A "peg" consists of a schwa plus a vowel; a "cord" consists of a vowel followed by a consonant, or a mater lectionis ${ }^{10}$, or a mater lectionis plus a consonant. Schirman simplified the system: all meters can be accounted for by two constituents only: schwa and vowel. Intuitively, we perceive a schwa plus a vowel as two units rather than one "peg". While I embrace Schirman's simplification, I raise the question whether the "peg" could have psychological reality, that is, whether what on a concrete level is perceived as two immediately-observable constituents, can be experienced at an abstract level as one category. To explore this, one must find at least two alternative performances, one in which an immediately-observable schwa plus a full vowel suggest a unified abstract category that cannot directly be perceived, and one performance in which they do not suggest such an abstract category - and see the different underlying acoustic structures. Obviously, no such readings are available. The only thing we can do is to invoke the precedent of disyllabic constituency of metrical position in English poetry, where we do have relevant performances. This precedent suggests that pegs may have psychological reality, but we lack evidence to decide whether this was, indeed, the case.

10 In the spelling of Hebrew and some other Semitic languages, matres lectionis (from Latin "mothers of reading", singular form: mater lectionis, from Hebrew: אָם קְריאָה ) are certain consonants that are used to indicate a vowel. The letters that do this in Hebrew are aleph $\mathrm{N}$, he ה, waw and yod '. The yod and waw in particular are more often vowels than they are consonants. 


\section{Appendix}

It is frequently assumed that it is the phonological, not the acoustic-phonetic information that counts in poetic rhythm. When I started with the instrumental analysis of recorded readings I, too, believed that what counts is which word or syllable is highlighted by the intonation peak. However, a few British phoneticians shamelessly explored some subtler alignments on the sub-phonemic level. When I encountered this, I discovered that those subtle alignments may account for strong intuitions regarding poetry recital that could not be accounted for in terms of stress peaks and intonation peaks alone.

Gerry Knowles (1992) explores the alignment of the F0 contour with vowels and consonants.

Although the effect of a tone might be to highlight a whole word or phrase, its focus is on a single syllable. Within the syllable it focuses on the vowel, and if the vowel is a diphthong, on one of the elements of the diphthong. Ultimately, within the relevant vowel there is a single point which appears to be the focus of accentuation. (Knowles 1992: 294)

Knowles calls this point the accent point. Such points may be located in various places in the vowel. Accordingly, he speaks of early-peaking and latepeaking, as the case may be (Ladd 1999 speaks of "delayed peak"; see also House, Wichman 1996). "Peak position would seem to be a continuous variable" (Knowles 1992: 294). For our present interest it is important that peak position may affect the grouping of syllables. The results of Knowles's research are completely independent from the needs of the present inquiry. He suggests the possibility that behind the phonological contrast of tone there is a functional contrast between an "initial" marker and a "final" marker.

Looking at all final tones before different kinds of boundary it was found that the greater the boundary the earlier the peak, with the earliest peaks preceding the silent pauses forming a major tone group boundary. The position with regard to initial position is not so clear: the latest peaks follow [...] pauses [...] within a major tone group [...]. Tones at the beginning of a major tone group are neither early nor late (Knowles 1992: 296; italics added).

In recorded readings of poetry, we find a greater than usual number of late peaking. Late peaks sometimes may not serve as "initial markers" as Knowles pointed out, because it sometimes occurs near the meeting of two linguistic units, toward the end of the earlier one. Cognitive poetics assumes that such 
"initial" and "final" markers are not just arbitrary conventions, but reflect some perceptual dynamics exploited by rhythmic solutions as well. I shall attempt to account for the effects of early and late peaking by what the Gestalt theorists call "perceptual forces". This notion is based on the Gestalt assumption that a perceptual unit tends to preserve its integrity by resisting interruptions. I shall introduce the issue by way of Arnheim's explorations of the phenomenon in visual perception, and then discuss it with reference to speech perception,

Two aspects of Knowles's foregoing discussion of peaking are of interest for our present inquiry. First, late peaking at the beginning of a tone group tends to have a forward rather than a backward grouping effect. And that it tends to be associated with minor rather than with major tone group boundaries. More is unknown than known about late peaking; so, the issue must be handled very carefully. But the finding concerning the tendency for late-peaking to begin rather than end a group may gain some support from Gestalt theory. We may be up against what Arnheim called perceptual forces. These forces are supposed to be inherent in both visual and aural perception. The existence of perceptual forces is most conspicuous in visual perception and this is the domain primarily explored by Gestalt psychologists.

At the beginning of his 1967 book, Arnheim demonstrates "the hidden structure of a square" by placing a black cardboard disk in various positions on a white square. Thus he "maps out" regions of tension and of balance. In Figure 12.1, the disk lies slightly off the centre. "In looking at the disk we may find that it does not merely occupy a certain place but exhibits restlessness. This restlessness may be experienced as a tendency of the disk to get away from where it is placed or, more specifically, as a pull in a particular direction - for example, toward the centre" (Arnheim 1967: 2).

Psychologically, the pulls in the disk exist in the experience of any person who looks at it. Since these pulls have a point of attack, a direction and an intensity, they meet the conditions established by physicists for physical forces (ibid., 6). Although perceptual forces are not physical in the sense that gravity is, "there is no point in calling these forces 'illusions.' They are no more illusory than colours, which are attributed to the objects themselves, although they are actually nothing but the reactions of the nervous system to light of particular wave lengths" (ibid.: 8). 


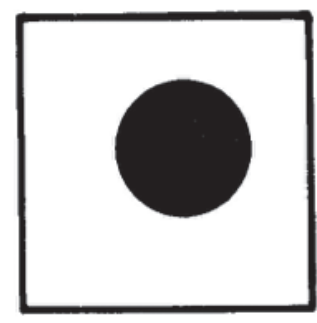

Figure 12.1

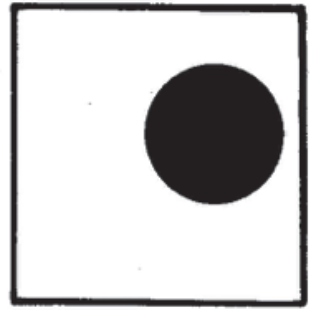

Figure 12.2

The sceptical reader may object: "Let us grant that these 'perceptual forces' do exist in visual patterns (or even in musical patterns). But verbal expression may be quite different. It introduces referential meaning through an arbitrary system of linguistic structures. How can we know that your 'perceptual forces' survive in such a complex system, too?" I shall make a brief attempt to meet the above objection by referring to psycholinguistic experiments by way of testing the psychological reality of constituent or phrase structure of sentences, performed by Fodor, Bever and Garret at MIT.

These researchers devised an ingenious technique for revealing the presence of phrase boundaries in the perception of sentences. The technique is based on the Gestalt assumption that a perceptual unit tends "to preserve its integrity by resisting interruptions" (Fodor, Bever 1965: 415). In the experiment of Fodor and Bever, subjects listened to a sentence during which a click occurred, and immediately afterward were required to write down the sentence and indicate where the click had occurred. If a phrase is a perceptual unit, subjects should tend to hear a click which occurred during a phrase as having occurred between the phrases.

One of their sentences was "That he was happy was evident from the way he smiled". This sentence has a major break between "happy" and "was". A click was placed at various positions in this sentence. [...] Each subject heard the sentence with only one click on it.

Fodor and Bever found that subjects were most accurate in locating the click which occurred between the two major phrases of the sentence - i.e., between "happy" and "was" in the above example. Clicks occurring before this break tended to be displaced towards the right (i.e., into the break), and those occurring after the break towards the left (i.e., again into the break). Fodor and Bever conclude that their findings "appear to demonstrate that the major syntactic break plays an important role in determining the subjective location of noises perceived during speech", thus supporting the hypothesis that "the unit of speech perception corresponds to the constituent". One might call these results 
into question on the suspicion that the major syntactic break is signalled by some acoustic means, such as pause. In additional research, however, Garret, Bever and Fodor (1966) have demonstrated that there are no clear acoustic cues that mark the breaks between constituent phrases. The most dramatic evidence of this surprising fact comes from an experiment comparing pairs of sentences such as:

(1) As a result of their invention's influence the company was given an award.

(2) The chairman whose methods still influence the company was given an award.

When subjects were asked where they hear the longest pause in the sentences, they report - as one might expect - that they hear a pause in (1) between "influence" and "the", and in (2) between "company" and "was". The perceived pause thus corresponds to the major constituent boundaries in the two sentences.

The ingenious part of the experiment comes next. The two sentences were recorded on tape, and the two italicized segments were interchanged. [...] Subjects' perception of pause location, however, was unchanged. The same was true of click displacement. As indicated by asterisks in the two sentences above, a click occurred either during "company" or "was". The perception of click location, however, was significantly different for the two sentences. The click in sentence (1) tended to be heard between "influence" and "the", and in (2) between "company" and "was". But remember the sentences were acoustically identical. (Slobin 1971: 25-26; italics in original)

For our present purpose, these results have two important implications: first, that perceptual forces do exist in a linguistic environment; second, perceptual forces in a linguistic environment are crucially influenced by the intruding event's coincidence with, or distance from, the boundary of the perceptual unit. In poetic prosody, however, there is a further complication. One cannot elicit perceptual forces with the help of some extra-linguistic click. The immediately observable exponents of all the perceptual units in poetry must be linguistic units. It may well be that Knowles's finding regarding late peaking suggests that these forces are active on the sub-phonemic level too. Indeed, the more examples I find in poetry reading, the more I become convinced of this. If the intonation peak hits the vowel in the middle, it enhances stability; if it hits off-center, the nearer the hit to the boundary, the stronger the pull to it. Such perceptual force may have enormous rhythmic as well as emotional effect.

According to Knowles, then, early and late peaking may serve as an "initial" marker and a "final" marker; according to Robert Ladd, delayed peak serves 
to foreground emotional qualities in the message; according to the present conception, in poetry they may serve all these functions, but most frequently they have a different function, the solution of rhythmic problems. Thus, they are more frequent in poetry than in everyday language.

For the purposes of the present article, the foregoing discussion suggests an additional possibility of great importance. The same principle that governs the psychological reality of syntactic boundaries should govern the psychological reality of versification boundaries as well. Thus, when a versification boundary intrudes upon a linguistic unit, or a linguistic boundary intrudes upon a versification unit, similar pulls and pushes should arise as with intruding extralinguistic clicks or intonation peaks. A mentalistic conception of poetry assumes that the same noises are the exponents of both linguistic and versification structures, and both have the same kind of psychological reality.

\section{References}

Arnheim, Rudolf 1967. Art and Visual Perception. London: Faber.

Bahat, Avner 2016. Qolot miqedem umiyam - mehqarim bəmuzika yehudit vayisraelit.

Chatman, Seymour 1965. A Theory of Meter (Janua Linguarum. Series Minor 36). The Hague: Mouton.

Chatman, Seymour 1966. On “the Intonational Fallacy”. In: Quarterly Journal of Speech 52(3), 283-286. https://doi.org/10.1080/00335636609382792

Fodor, Jerry A.; Bever, Thomas G. 1965. The Psychological Reality of Linguistic Segments. In: Journal of Verbal Learning and Verbal Behavior 4(5), 414-420. https://doi.org/10.1016/S0022-5371(65)80081-0

Fry, Dennis B. 1958. Experiments in the Perception of Stress. In: Language and Speech 1(2), 126-151. https://doi.org/10.1177/002383095800100207

Garrett, Merill; Bever, Thomas G.; Fodor, Jerry A. 1966. The Active Use of Grammar in Speech Perception. In: Perception and Psychophysics 1(1), 30-32.

https://doi.org/10.3758/BF03207817

Greene, Ronald (ed.) 2012. The Princeton Encyclopedia of Poetry and Poetics. Fourth edition. Princeton, Oxford: Princeton University Press.

Halle, Morris; Keyser; Samuel Jay 1966. Chaucer and the Study of Prosody. In: College English 28(3), 187-219. https://doi.org/10.2307/374038 
Halle, Morris; Keyser, Samuel Jay 1971. English Stress: Its Form, Its Growth and Its Role in Verse. New York: Harper and Row.

Herrnstein-Smith, Barbara 1968. Poetic Closure: A Study of How Poems End. Chicago: University of Chicago Press.

House, Jill; Wichmann, Anne 1996. Investigating Peak Timing in Naturally-Occurring Speech: From Segmental Constraints to Discourse Structure. In: Speech, Hearing and Language: work in progress 9: 99-117.

Kiparsky, Paul 1975. Stress, Syntax, and Meter. In: Language 51(3), 576-616. https:// doi.org/10.2307/412889

Kiparsky, Paul 1977. The Rhythmic Structure of English Verse. In: Linguistic Inquiry $8(2), 189-247$.

Knowles, Gerry 1992. Pitch contours and tones in the Lancaster/IBM spoken English corpus. In: Leitner, Gerhard (ed.), New Directions in English Language Corpora: Methodology, Results, Software Developments (Topics in English Linguistics 9). Berlin, New York: Mouton de Gruyter, 289-299.

Ladd, Robert D. 1996. Intonational Phonology (Cambridge Studies in Linguistics 79). Cambridge: Cambridge University Press.

Margolis, Joseph 1962. The Logic of Interpretation. In: Margolis, Joseph (ed.), Philosophy Looks at the Arts: Contemporary Readings in Aesthetics. New York: Charles Scribner's Sons, 108-118.

Meyer, Leonard B. 1956. Emotion and Meaning in Music. Chicago: University of Chicago Press.

Meyer, Leonard B. 1963. The End of the Renaissance? Notes on the Radical Empiricism of the Avant-garde. In: Hudson Review 16(2), 169-185.

https://doi.org/10.2307/3848629

Morag, Šlomo; Šiloaḥ, Amnon 1995. Mišqal u-neSimah be-fiyyutei qehillot Teiman u-Sfarad. Le-roš Yosef: Mehquarim be-hokhmat Yisrael - Teširat hoqarah la-rav Yosef Qapah, ed. Yosef Tobi. Jerusalem, 435-456.

Rozen, Tova 1994. Hamahălakh hastrofi bəširat Yohuda Halevi - poetika alternativit? Batokh Reuven Tsur vaTova Rozen (Sorkhim) Sefcr hayovel laYisrael Levin. Tel Aviv: Universitat Tel Aviv, 315-328.

Schirman, Hayim 1979. Keiṣad yeš ladaklem ct haširim hašqulim šcl mšorrenu haspharadiio? Lotoldot hašira vəhadrama haSivrit. Yerušalaim: mosad Bialik.

Schramm, Wilbur L. 1935. Approaches to a Science of English Verse. Iowa City: Iowa University. 
Slobin, Dan I. 1971. Psycholinguistics. Glenview, Ill.: Scotts, Foresman and Co.

Smart, John Jamieson Carswell. 1953. Theory construction. In: Flew, Anthony G. N. (ed.), Logic and Language. Second Series. Oxford: Blackwell, 222-242.

Tsur, Reuven 1977. A Perception-Oriented Theory of Metre. Tel Aviv: The Porter Institute for Poetics and Semiotics.

Tsur, Reuven 1999. Ibn Khalphun's "When Desire Awakens Me": On Relativism, Absolutism and Perspectivism in the Study of Mediaeval Hebrew Poetry. In: Jewish Studies Quarterly 6(2), 113-139.

Tsur, Reuven 2012. Poetic Rhythm: Structure and Performance: An Empirical Study in Cognitive Poetics. Revised and expanded edition. Sussex Academic Press: Brighton and Portland.

Tsur, Reuven; Gafni, Chen 2018. Enjambment - Irony, Wit, Emotion. A Case Study Suggesting Wider Principles. In: Studia Metrica et Poetica 5(2), 7-28. https://doi.org/10.12697/smp.2018.5.2.01

Weitz, Morris 1956. The Role of Theory in Aesthetics. In: The Journal of Aesthetics and Art Criticism 15(1), 27-35. https://doi.org/10.2307/427491

Wellek, René 1960. Closing Statement. In: Sebeok, Thomas A. (ed.), Style in Language. Cambridge, Mass.: MIT Press, 408-419.

Wellek, René; Warren, Austin 1949. Theory of Literature. New York: Harcourt, Brace \& Co.

Whissell, Cynthia 1999. Phonosymbolism and the Emotional Nature of Sounds: Evidence of the Preferential Use of Particular Phonemes in Texts of Differing Emotional Tone. In: Perceptual and Motor Skills 89(1), 19-48. https://doi.org/10.2466/pms.1999.89.1.19

Willett, Steven J. 2001. Book Review: Reuven Tsur, Poetic Rhythm: Structure and Performance - An Empirical Study in Cognitive Poetics. Berne: Peter Lang, 1998. In: Journal of Pragmatics 33(2), 333-338. https://doi.org/10.1016/S0378-2166(00)00023-0

Willett, Steven J. 2005. Reconsidering Reuven Tsur's Poetic Rhythm: Structure and Performance - An Empirical Study in Cognitive Poetics. In: Journal of Pragmatics 37(4), 497-503. https://doi.org/10.1016/S0378-2166(00)00023-0

Wimsatt, William K., Jr.; Beardsley, Monroe C. 1959. The Concept of Metre: An Exercise in Abstraction. In: PMLA 74(5), 585-598. https://doi.org/10.2307/460509

Yaraman, Sevin H. 2002. Revolving Embrace: The Waltz as Sex, Steps, and Sound. Hillsdale, N.Y.: Pendragon Press. 